\title{
THE ROLE OF ALTERED GLYCOSYLATION IN HUMAN NUCLEUS PULPOSUS CELLS IN INFLAMMATION AND DEGENERATION
}

\author{
K. Joyce ${ }^{1,2}$, I.L. Mohd Isa ${ }^{2,5}$, A. Krouwels ${ }^{3}$, L. Creemers ${ }^{3}$, A. Devitt2, ${ }^{2,4}$ and A. Pandit ${ }^{2, *}$ \\ ${ }^{1}$ School of Medicine, National University of Ireland, Galway, Ireland \\ ${ }^{2}$ CÚRAM, SFI Research Centre for Medical Devices, Biomedical Sciences Building, \\ National University of Ireland Galway, Ireland \\ ${ }^{3}$ Department of Orthopaedics, University Medical Centre Utrecht, Utrecht, the Netherlands \\ ${ }^{4}$ Department of Orthopaedic Surgery, Galway University Hospital, Galway, Ireland \\ ${ }^{5}$ Department of Orthopaedics and Traumatology, Faculty of Medicine, \\ The National University of Malaysia, Malaysia
}

\begin{abstract}
Intervertebral disc (IVD) degeneration causes low-back pain through disc compression, prolapse and herniation. Inflammation of the IVD and subsequent degeneration produce altered glycosylation profiles in several animal models of IVD injury and ageing, although the function of this altered glycosylation pattern in humans is unknown. Altered $N$-glycome, specifically sialylated and fucosylated $N$-glycosylation motif expression, might play a role in inflammation and disease progression. Healthy (foetal and adolescent idiopathic scoliosis) and degenerated (lumbar degeneration) human IVD glycosylation patterns were studied using lectin histochemistry. Small-molecule fluorinated sugar analogues (3Fax-Peracetyl Neu5Ac; 2F-PeracetylFucose) were used to inhibit sialylation and fucosylation in an in vitro model of inflammation, to investigate their effects on the glycosignature, cell metabolism, extracellular matrix synthesis and cell migration. The effects of interleukin (IL)- $1 \beta$, tumour necrosis factor (TNF)- $\alpha$ and IL-6 on glycosylation in human nucleus pulposus cells were investigated by lectin histochemistry, PCR and enzyme-linked immunosorbent assay (ELISA). In the in vitro model of IVD degeneration, cytokine-induced inflammation-induced hypersialylation was observed, as indicated by Sambucus nigra I binding. However, this modification was inhibited by the sialyltransferase inhibitor. Inhibition of sialylation and fucosylation modulates cell migration and protein translation of catabolic enzymes in response to inflammation. The altered patterns of glycosylation in human tissue in degeneration was consistent with previous IVD studies in murine, bovine and ovine models. The present study was the first functional investigation of glycosylation in human degenerated IVD, elucidating the role of the glycome in disease progression and identified potential therapeutic targets for future regenerative therapies.
\end{abstract}

Keywords: Glycosylation, inflammation, intervertebral disc, degeneration.

*Address for correspondence: Prof Abhay Pandit, CÚRAM, SFI Research Centre for Medical Devices, National University of Ireland, Galway, Ireland.

Email: abhay.pandit@nuigalway.ie

Copyright policy: This article is distributed in accordance with Creative Commons Attribution Licence (http://creativecommons.org/licenses/by-sa/4.0/).

\begin{tabular}{|c|c|c|c|}
\hline & List of Abbreviations & $\begin{array}{l}\text { BSA } \\
\text { CD }\end{array}$ & $\begin{array}{l}\text { bovine serum albumin } \\
\text { cluster of differentiation }\end{array}$ \\
\hline AAL & Aleuria aurantia lectin & CMP & cytidine- $5^{\prime}$-monophosphate \\
\hline ACAN & aggrecan & COL1 & collagen type 1 \\
\hline ADAMTS-4 & $\begin{array}{l}\text { ADAM metallopeptidase with } \\
\text { thrombospondin type } 1 \text { motif } 4\end{array}$ & $\begin{array}{l}\text { COL2 } \\
\text { Con A }\end{array}$ & $\begin{array}{l}\text { collagen type } 2 \\
\text { concanavalin A }\end{array}$ \\
\hline AF & annulus fibrosus & DAPI & 4,6-diamidino-2-phenylindole \\
\hline AIS & adolescent idiopathic scoliosis & DSA & Datura stramonium agglutini \\
\hline ATP & adenosine triphosphate & ECAR & extracellular acidification rate \\
\hline BCA & bicinchoninic acid & ECM & extracellular matrix \\
\hline
\end{tabular}




\begin{tabular}{|c|c|}
\hline ELISA & $\begin{array}{l}\text { enzyme-linked immunosorbent } \\
\text { assay }\end{array}$ \\
\hline ER & endoplasmic reticulum \\
\hline EthD-1 & ethidium homodimer-1 \\
\hline FAK & focal adhesion kinase \\
\hline FBS & foetal bovine serum \\
\hline FCCP & carbonylcyanide-4-phenylhydrazone \\
\hline FITC & fluorescein isothiocyanate \\
\hline FUT & fucosyltransferase \\
\hline GA & Golgi apparatus \\
\hline IL & interleukin \\
\hline IVD & intervertebral disc \\
\hline MAA & Maackia Amurensis II \\
\hline ManNAc & $N$-acetylmannosamine \\
\hline MRI & magnetic resonance imaging \\
\hline MMP & matrix metalloproteinase \\
\hline Neu5Ac & $N$-acetylneuraminic acid \\
\hline $\mathrm{NF}-\kappa \mathrm{B}$ & nuclear factor kappa B \\
\hline NP & nucleus pulposus \\
\hline OCR & oxygen consumption rate \\
\hline OCT & optimal cutting temperature \\
\hline OD & optical density \\
\hline PBS & phosphate-buffered saline \\
\hline PFA & paraformaldehyde \\
\hline PNA & peanut agglutinin \\
\hline $\mathrm{P} / \mathrm{S}$ & penicillin/streptomycin \\
\hline SEM & standard error of the mean \\
\hline SNA & Sambucus nigra I \\
\hline ST & sialyltransferase \\
\hline ST3Gal NAc IV & $\begin{array}{l}\text { ST6 } N \text {-acetylgalactosaminide alpha- } \\
\text { 2,6-sialyltransferase } 4\end{array}$ \\
\hline ST6Gal & $\begin{array}{l}\text { ST6 beta-galactoside alpha-2,6- } \\
\text { sialyltransferase }\end{array}$ \\
\hline TBS & Tris-buffered saline \\
\hline TGF- $\beta$ & transforming growth factor beta \\
\hline TIMPs & tissueinhibitors of metalloproteinases \\
\hline TNF- $\alpha$ & tumour necrosis factor alpha \\
\hline TRITC & tetramethylrhodamine \\
\hline UEA-I & Ulex europeaus lectin agglutinin I \\
\hline UPLC-MS & $\begin{array}{l}\text { ultra-performance liquid } \\
\text { chromatography-mass spectrometry }\end{array}$ \\
\hline WFA & Wisteria floribunda agglutinin \\
\hline WGA & wheat germ agglutinin \\
\hline$\alpha \mathrm{MEM}$ & $\begin{array}{l}\text { minimum essential medium Eagle } \\
\text { alpha modification }\end{array}$ \\
\hline
\end{tabular}

\section{Introduction}

IVD degeneration is a significant cause of lowback pain through disc compression, prolapse and herniation (Zheng and Chen, 2015). Inflammation of the IVD and its subsequent degeneration produce altered glycosylation profiles in several animal models of IVD injury and ageing, although the function of this altered glycosylation pattern in humans is unknown. Many cellular processes are altered in IVD degeneration. Factors such as cellular nutrition, $\mathrm{pH}$, oxygen tension and altered mechano-sensing cause the differential regulation of cellular pathways towards a pro-inflammatory, senescent phenotype (Adams et al., 2009; 2015). This is further characterised by reduced ECM synthesis, upregulation of catabolic enzymes and increased apoptotic signalling (Buckwalter, 1995). Glycosylation of glycoproteins contributes to the functional diversity required to generate extensive variation in activity and regulation of cellular pathways (Paulson and Colley, 1989). Glycosylation mediates critical processes such as protein synthesis (Komekado et al., 2007), receptor expression and activity (Da Silva Correia and Ulevitch, 2002; Liu et al., 2011) as well as enzyme functions (Kim and Varki, 1997).

Glycans are post-translational modifications coded by over 500 genes, present on the peptide backbone of glycoproteins in $\mathrm{N}$ - and $\mathrm{O}$-linked conjugations. Glycan synthesis starts on the rough ER in a non-template driven process coordinated by glycosyltransferases and glycohydrolases. Many glycosyltransferases exist and some are tissue-specific (Raman et al., 2005). In the ER, glycosyltransferases add monosaccharide residues to the glycan core, which is refined in the GA. Glycosidases/ glycohydrolases cleave terminal monosaccharides and primarily reside in the ER but are also soluble. Both glycosyltransferases and glycosidases regulate the biosynthesis and degradation of glycoconjugates in a tightly regulated manner.

While many aspects of the glycome have been characterised, sialylated and fucosylated motifs have been intensely investigated due to the modulatory effects of these modifications. Sialylated glycans play a crucial role in cell-to-cell interactions, cell signalling, migration and development (Bhide and Colley, 2017; Chen and Varki, 2010; Natoni et al., 2019). STs are part of the glycosyltransferase enzyme family that play an integral role in the biosynthesis of sialylated glycans and carbohydrate-containing moieties. STs are bound to the GA by a transmembrane anchor, orientated with the active site towards the lumen ( $\mathrm{Li}$ and Chen, 2012). Sialic acid may be $\alpha-(2,3 / 6 / 8)$-conjugated to galactose. Sialic acid linkage is modulated by the NF- $\kappa$ B pathway, upregulating ST6Gal I mRNA over ST3GalNAc IV mRNA expression specifically, favouring $\alpha-(2,6)$ over $\alpha-(2,3)$ expression (Higai et al., 2006). $\alpha-(2,6)$-sialylation is crucial for osteoclast differentiation (Takahata et al., 2007).

Fucose is another essential glycan residue expressed on the cell surface, playing an essential role in various biological processes including tissue development, angiogenesis, selectin-mediated cell adhesion, leukocyte localisation, inflammation, self-recognition and cell-to-cell interactions (Becker and Lowe, 2003). $\alpha-(1,2)$ fucosylation, regulated by two fucosyltransferase-coding genes, FUT1 and FUT2, is responsible for $\mathrm{H}, \mathrm{A}$ - and B-blood and Lewis $Y$ antigens (Kyprianou et al., 1990). $\alpha-(1,3 / 4)$ fucosylation is present in glycosylation motifs such as Lewis X/sialyl-Lewis X and is governed by FUT3-7 (Henry et al., 1995; Legault et al., 1995). Finally, $\alpha-(1,6)$ fucosylation, is widely expressed in mammalian 
tissues and ubiquitously expressed across many glycoproteins and glycolipids (Miyoshi et al., 1999).

The addition of sialic acid by sialyltransferase to a terminal galactose on $\mathrm{N}$ - and $\mathrm{O}$-glycans is increased in IVD degeneration (Collin et al., 2016; Kazezian et al., 2017; Mohd Isa et al., 2018). The glycoprofile of the human disc has been investigated by lectin histochemistry and N-glycan profiling by UPLCMS, revealing an increase in global sialylation and fucosylation [Joyce et al. (2018) The glycomic profile of the intervertebral disc in health and degeneration for biomaterial functionalization. Orthop Proc 100B. DOI: 10.1302/1358-992X.2018.16.117; conference abstract]. TNF- $\alpha$, a pro-inflammatory cytokine, increases the expression of sialyltransferase (ST3GalIII/IV) and FUT3/4 - to increase sialylation and fucosylation, respectively - as well as of sialyl-Lewis $X$ epitope in human bronchial mucosa (Watanabe et al., 2004). IL-6 and IL-8 also increase the expression of glycosyltransferases (FUT3/11 and ST3Gal2/6) and sulphotransferases (carbohydrate sulphotransferase four genes) in bronchial mucosa (Groux-Degroote et al., 2008). IL-1 $\beta$ and TNF- $\alpha$ upregulate the expression of $\alpha-(2,3)$ sialyltransferases in primary human chondrocytes in vitro on both $\mathrm{N}$ - and O-glycans (Pabst et al., 2010). The shift toward $\alpha-(2,3)$ sialylation increases the population of complex-type $N$-glycans. TNF- $\alpha$ decreases the expression of core fucosylation in primary human chondrocytes (Pabst et al., 2010). It is unknown what role the glycome plays in modulating the cellular microenvironment and response to the noxious environment of the degenerated IVD.

3Fax-Peracetyl Neu5Ac (Neu5Ac-inhib) is an ideal candidate molecule to inhibit sialyltransferase enzymes to assess the downstream effects of glycosylation inhibition (Rillahan et al., 2012). Neu5Acinhib is a fluorinated analogue of sialic acid, which is readily taken into cells by diffusion and converted into a corresponding donor substrate analogue of CMP-Neu5Ac. Although it closely resembles the natural CMP-sialic acid substrate, this fluorinated derivative destabilises the oxocarbenium transition state needed for Neu5Ac transfer to galactose residues (Montgomery et al., 2016). The accumulation of this fluorinated CMP-Neu5Ac analogue also inhibits de novo synthesis of CMP-Neu5Ac through a negative feedback loop (Hinderlich et al., 2015). Competitive inhibition of the sialyltransferase enzyme is a novel approach to glycosylation inhibition to elucidate the role of sialylation in IVD degeneration. An equivalent molecule, 2F-Peracetyl-Fucose (fucose-inhib), inhibits fucosyltransferases non-specifically to block de novo fucosylation (Rillahan et al., 2012).

It was hypothesised that glycosylation plays a role in the degeneration cascade in the IVD and targeted inhibition of sialylation and fucosylation may modulate the glycomic response to inhibit or dampen cytokine-mediated signalling in NP cells. The present study evaluated the phenotype of glycosignature of healthy and degenerated human NP and established an in vitro model of IVD degeneration in NP cells by cytokine-induced inflammation, demonstrating the aberrant expression of sialylation and fucosylation.

The effects of glycosylation inhibitors on sialylation and fucosylation expression were investigated in human NP cells in an inflammatory environment to assess the efficacy of targeting aberrations in the glycosylation profile. Glycosylation inhibitors, Neu5Ac-inhib and Fucose-inhib, efficiently inhibited the hypersialylation and hyperfucosylation observed in the cytokine-induced inflammatory model without any negative impact on cell survival. This inhibition restored glycosylation to physiological levels, which affected cell protein synthesis, inflammatory response, cell migration and respiration. To the authors' knowledge, this is the first study to demonstrate the ability of glycosylation inhibitors to restore physiological glycosylation in human NP cells and to demonstrate the role of glycosylation in degeneration. This may offer new molecular targets for biomaterial functionalisation in the future.

\section{Materials and Methods}

\section{Materials and reagents}

3Fax-Peracetyl Neu5Ac and 2F-Peracetyl-Fucose were purchased from Merck. 96-well glass coverslip microplates were purchased from Ibidi. All lectins were purchased from Vector Labs. Human recombinant IL-1 $\beta$, IL- 6 and TNF- $\alpha$ were purchased from Peprotech. RNeasy Mini Kit and Quantifast SYBR Green were purchased from Qiagen. qScript cDNA SuperMix ${ }^{\mathrm{TM}}$ was purchased from VWR. RNase inhibitor was purchased from Bioline. PCR primers were purchased from Eurofins. Human MMP-13 ELISA kit was purchased from Abcam. Teflon ${ }^{\mathrm{TM}}$ tape, Live/Dead ${ }^{\circledR}$ staining kit, alamarBlue ${ }^{\circledR}$ assay, DAPI, TaqMan ${ }^{\circledR}$ VIC $^{\circledR}$-labelled GAPDH primer and TaqMan ${ }^{\circledR}$ Universal PCR Master Mix, no AmpErase ${ }^{\circledR}$ UNG were purchased from Fisher Scientific. Primocin was purchased from InvivoGen. TaqMan FAM ${ }^{\mathrm{TM}}$ labelled COL1/2 primers were purchased from Thermo Fisher Scientific. All other materials and reagents were purchased from Sigma-Aldrich unless otherwise stated.

\section{Human IVD tissue collection and preparation for lectin histochemistry}

Discs from foetal and degenerated tissue were obtained from Utrecht University, the Netherlands. Collection of IVD specimens was performed according to the medical ethical regulations (protocol 12-364) of the University Medical Centre Utrecht (Utrecht, the Netherlands). Isolated discs were fixed in $10 \%$ formalin for $48 \mathrm{~h}$, decalcification of the vertebral bones was performed at $4{ }^{\circ} \mathrm{C}$ using 'Kristensen's decalcifying solution containing $18 \%$ $(\mathrm{v} / \mathrm{v})$ formic acid and $3.5 \%(\mathrm{w} / \mathrm{v})$ sodium formate. Then, tissue samples were washed with tap water overnight and soaked (how long?) at $4{ }^{\circ} \mathrm{C}$ in a $20 \%$ $(\mathrm{w} / \mathrm{v})$ sucrose solution until they were submerged in 
Table 1. Optimisation of glycosylation inhibition. 3Fax-Peracetyl Neu5Ac- and 2F-Peracetyl-Fucose-treated cells were cultured at various concentrations for $10 \mathrm{~d}$.

\begin{tabular}{|c|c|c|}
\hline Inhibitor & 3Fax-Peracetyl Neu5Ac (sialylation) & 2F-Peracetyl Fucose (fucosylation) \\
\hline \multirow{3}{*}{$\begin{array}{c}\text { Concentration of } \\
\text { inhibitor }\end{array}$} & $50 \mu \mathrm{mol} / \mathrm{L}$ & $50 \mu \mathrm{mol} / \mathrm{L}$ \\
\cline { 2 - 3 } & $300 \mu \mathrm{mol} / \mathrm{L}$ & $300 \mu \mathrm{mol} / \mathrm{L}$ \\
\cline { 2 - 3 } & $500 \mu \mathrm{mol} / \mathrm{L}$ & $500 \mu \mathrm{mol} / \mathrm{L}$ \\
\hline
\end{tabular}

Table 2. Lectin binding specificity and associated haptenic controls. Haptenic sugar is a monosaccharide/ disaccharide that is pre-incubated with the lectin to cause non-competitive inhibition, to investigate the non-site-specific binding of the lectin as a control. Haptenic sugar is applied during optimisation to ensure no non-specific binding of the lectin to the sample. Abbreviations: GalNAc, $N$-acetyl glucosamine.

\begin{tabular}{|c|c|c|}
\hline Lectin & Binding specificity & Haptenic sugar (100 $\mathbf{~ m m o l / L ) ~}$ \\
\hline SNA-I (Sambucus nigra I) & $\alpha-2,6$ sialylation & Lactose \\
\hline MAA-II (Maackia amurensis II) & $\alpha-2,3$ sialylation & Lactose \\
\hline AAL (Aleuria aurantia) & $\alpha-1,6$ fucose & Fucose \\
\hline UEA-I (Ulex europaeus agglutinin I) & $\alpha-1,2 / 3$ fucose & GlcNAc \\
\hline WGA (wheat germ agglutinin) & $\alpha-2,3 / 6$ sialylation, GlcNAc & Galactose \\
\hline PNA (peanut agglutinin) & $\beta-1,3$ galactosylation & Galactose \\
\hline GS-I-B4 (Griffonia simplicifolia & Terminal $\alpha$-linked galactosylation & Mannose \\
\hline Con A (concanavalin A) & $\begin{array}{c}\alpha \text {-linked mannosylation, } \\
\text { glucosamine and GlcNAc }\end{array}$ & \\
\hline
\end{tabular}

Table 3. Primers utilised in the qRT-PCR analysis.

\begin{tabular}{|c|c|c|c|}
\hline Gene & Forward & Reverse & Base pairs \\
\hline Collagen I & 5' GATTCCCTGGACCTAAAGGTGC 3' & 5' AGCCTCTCCATCTTTGCCAGCA 3' & 19 \\
\hline Collagen II & 5' CCTGGCAAAGATGGTGAGACAG 3' & 5' CCTGGTTTTCCACCTTCACCTG 3' & 19 \\
\hline $18 S$ & 5' GTCTCCTCTGACTTCAACAGCG 3' & 5' ACCACCCTGTTGCTGTAGCCAA 3' & 19 \\
\hline
\end{tabular}

it. Tissues were embedded in OCT compound, snapfrozen in an isopentane bath cooled by liquid nitrogen and stored at $-80{ }^{\circ} \mathrm{C}$ until sectioning at $10 \mu \mathrm{m}$ using a cryostat (Leica CM1850).

\section{Lectin staining}

Lectin staining was performed as previously described (Mohd Isa et al., 2018). Briefly, the staining was carried out at room temperature. Tissue sections were initially washed in TBS-T (TBS with $0.05 \%$ Triton $\mathrm{X}-100)$. TBS is an isotonic, non-toxic $\mathrm{pH}$-stabilising solution used for membrane washing. Triton $\mathrm{X}$ is used as a detergent to permeabilise cell membranes within the tissue to promote lectin binding intracellularly. Then, sections were blocked using 2 \% BSA (A7638, Sigma) for $1 \mathrm{~h}$. BSA is a concentrated protein buffer used to compete with lectins for non-specific epitope binding in the sample. High concentrations of protein competitors out-compete lectin binding and reduce background noise during imaging. From this point onwards, darkness was maintained for lectin staining. Eight lectins (SNA-I, MAA, WGA, Con A, UEA-I,
WFA, DSA and PNA) (either FITC-conjugated or TRITC-conjugated, EY Laboratories Inc., San Mateo, CA, USA) were prepared in TBS-T and incubated for $1 \mathrm{~h}$ with the tissue samples (lectin specificity outlined in Table 2.). These lectins were chosen to investigate various glycosylation motifs common to human cells, including mannosylation, sialylation, galactosylation, fucosylation and GlcNAcylation to capture an overall impression of the glycosignature of these cells. Tissues were washed and counterstained with 1 : 2,000 $0.04 \%$ DAPI, a fluorescent stain that binds to A-T regions of the DNA, thus highlighting the cell nucleus. Slides were washed in TBS-T before coverslip mounting using ProLong ${ }^{\circledR}$ Gold Antifade Mountant (Life Technologies). Imaging was performed within $5 \mathrm{~d}$. All washes were performed 3 times for 5 min each between incubations, unless otherwise stated.

The TBS used was a modified recipe of $20 \mathrm{mmol} / \mathrm{L}$ Tris-HCl, $100 \mathrm{mmol} / \mathrm{L} \mathrm{NaCl}, 1 \mathrm{mmol} / \mathrm{L} \mathrm{CaCl}_{2}$, $1 \mathrm{mmol} / \mathrm{L} \mathrm{MgCl}_{2}$, brought to $\mathrm{pH} 7.2$ using concentrated $\mathrm{HCl}$. 


\section{Inhibition controls}

Haptenic sugar inhibition controls were carried out in parallel during the optimisation phase, according to Table 2. A haptenic sugar is a monosaccharide or disaccharide that can inhibit binding of a lectin. $100 \mathrm{mmol} / \mathrm{L}$ solutions of the appropriate sugar in TBS-T were co-incubated with the corresponding lectin for $1 \mathrm{~h}$ to verify that the lectin binding was glycan-mediated.

Lectin image analysis and stereology quantification Quantification was carried out on the foetal samples $(n=3)$ and degenerated samples $(n=3)$. Stereology quantification was adopted to calculate the percentage (\%) volume fraction of detectable lectin binding in each tissue sample. Lectin histochemical binding fluorescence was obtained from at least 5 microscopical views of each slide with 3 technical and 2 biological replicates using the FIJI/ImageJ software version $1.51(\mathrm{NIH})$. Confocal images were converted to binary mode ( 8 bit) and adjusted to the optimal threshold of positive staining and total area. Volume fraction was calculated by quantifying the area fraction of the positively stained matrix component divided by the total area and converting into a percentage (\%) as below:

Percentage volume fraction $=$ area fraction $\times 100 \% /$ total area

\section{Human IVD tissue collection and cell isolation}

Ethical approval was sought and obtained from the NUI Galway Research Ethics Committee and Our Lady's Children's Hospital, Crumlin Research Ethics Committee for the collection and isolation of IVD cells. Degenerated cells were isolated from patients undergoing discectomy and fusion surgery to treat low-back pain after receiving patient consent (donor age: $36-72$ years old; $n=3$ ). Healthy cells were collected from adolescent patients undergoing spinal realignment surgery for AIS with appropriate assent and consent from parents/guardians (donor age: 9-16 years old; $n=3$ ). The authors acknowledge the limitations of using cells isolated from patients with AIS as "healthy" controls; however, they accept their use in the study based on their initial characterisation and phenotype, as presented in the Results section. Furthermore, all healthy cells were isolated from IVD of Pfirrmann grade I on MRI and degenerated cells were isolated from discs with confirmed Pfirrmann grade V (Pfirrmann et al., 2001). IVD tissues were collected from the surgical theatre and sorted at $4^{\circ} \mathrm{C}$ until processing for cell isolation within $4 \mathrm{~h}$ of procurement from the patient. AF and NP were already separated in the theatre as identified by the surgeon during discectomy. The tissue was weighed based upon an addition to a pre-weighed falcon tube containing PBS (pH 7.4) and $1 \% \mathrm{P} / \mathrm{S}$. The sample was centrifuged and supernatant aspirated. Red blood cell lysate was added at this point if tissue appeared bloodstained. After washing, the tissue was minced and a $0.2 \%$ pronase solution $(\mathrm{pH} 7.4)$ added for $1 \mathrm{~h}$ at $37^{\circ} \mathrm{C}$ on a shaker plate at $300 \mathrm{rpm}$. The tissue was washed twice with PBS and incubated in collagenase solution $(100 \mathrm{U} / \mathrm{mL}$ collagenase in $\alpha$-MEM and $10 \%$ FBS) ( $\mathrm{pH}$ 7.4). The sample was digested overnight and filtered through a $100 \mu \mathrm{m}$ cell strainer. The cell solution was centrifuged and washed before cell counting. Cells were plated at a density of 10,000 cells $/ \mathrm{cm}^{2}$. The plate was left untouched for a minimum of $4 \mathrm{~d}$ to allow cells to attach to the flask and medium was changed 2-3 times per week after that. Cells were passaged at approximately 70-80\% confluency and all experiments were performed on cells within passage 4 or sooner due to the loss of cell phenotype in 2D culture conditions.

\section{Cytokine-induced inflammation in IVD degeneration}

NP cells $\left(3 \times 10^{3}\right)$ were seeded on a glass surface Ibidi 96-well plate (Fig. 1). Cells were grown in complete medium containing $\alpha$-MEM, $10 \%$ FBS and $1 \% \mathrm{P} / \mathrm{S}$ at $37{ }^{\circ} \mathrm{C}$ in a humidified atmosphere of $5 \% \mathrm{CO}_{2}$. After $24 \mathrm{~h}$, cells were stimulated with a cytokine cocktail containing IL-1 $\beta$, TNF- $\alpha$ and IL- 6 at a concentration of $10 \mathrm{ng} / \mathrm{mL}$, which had each previously been shown to induce downstream upregulation of inflammatory markers by $\mathrm{qPCR}$ at the given concentration (Gao et al., 2019). The cytokine-containing medium was refreshed every $48 \mathrm{~h}$ for up to $10 \mathrm{~d}$. Lectin histochemistry was performed at 24, 72 and $168 \mathrm{~h}$ to investigate the effect of cytokine-induced inflammation on glycosylation motif expression in vitro.

\section{Cell viability assay for glycosylation inhibitors}

The cytotoxicity of glycosylation inhibitors was investigated by incubating NP cells with each inhibitor. NP cells were plated at a density of 3,000 cells/well in a 96-well plate and treated with varying concentrations of glycosylation inhibitors (Table 1) for $10 \mathrm{~d}$ at $37^{\circ} \mathrm{C}, 5 \% \mathrm{CO}_{2}$ in a humidified atmosphere. The initial concentrations used for optimisation were based on the manufacturer's recommendations for a range of efficacy dependent on cell type. Then, cells were washed with PBS and incubated in the dark for $5 \mathrm{~h}$ with alamarBlue ${ }^{\circledR}$ assay solution (10: 1 dilution in complete culture medium). The supernatant was pipetted into a new well plate and absorbance was measured at $540 \mathrm{~nm}$ using a plate reader (Varioskan Flash ${ }^{\mathrm{TM}}$, Thermo Fisher Scientific). Measurements were normalised to appropriate controls and blanks. In parallel, cells were similarly seeded and underwent live/dead staining to assess cell survival. Cells were incubated with calcein AM and EthD-1 for 30 min to identify live and dead cells, respectively. Subsequently, cells were fixed and imaged using the Operetta ${ }^{\circledR}$ High Content Imaging System (PerkinElmer).

Reduction in sialylation and fucosylation by Neu5Ac-inhib and Fucose-inhib, respectively, was measured by staining intensity of given lectins. Cells were cultured over $10 \mathrm{~d}$, with medium changes 
every $48 \mathrm{~h}$ to replenish the inhibitor. After $10 \mathrm{~d}$, cells were fixed for $20 \mathrm{~min}$ using $4 \%$ PFA solution. Then, cells were blocked using periodate-treated BSA and stained with FITC-conjugated lectins. Samples were countered using DAPI or Hoescht and imaged using the PerkinElmer Operetta ${ }^{\circledR}$ High Content Imaging System. The imaging software was employed to identify each cell nucleus by the DAPI stain and then identify the surrounding cell membrane. The intensity of each membrane staining was calculated using the Harmony software (v3.1.1).

\section{Cell migration}

Sialylation inhibition was investigated in control and inflammatory cell culture to study its effect on cell migration. Cells were seeded at a density of 20,000 cells $/ 100 \mu \mathrm{L}$ in each culture insert. Each culture insert, developed for wound healing assays, contained two wells in which cells were allowed to attach, divided by a $500 \mu \mathrm{m}$ wall. A $500 \mu \mathrm{m}$ cell-free gap was created until the cells became confluent, after which the insert was removed. The migration of the cells was monitored over $72 \mathrm{~h}$, with images taken every $12 \mathrm{~h}$. The area of gap closure was measured by the area fraction of the cells spanning it. Cell migration of healthy NP cells was compared to that of cytokine-induced cells (IL-1 $\beta /$ IL-6/TNF- $\alpha$ ). Cytokineinduced cells were also treated with Neu5Ac-inhib and Fucose-inhib to investigate the role of sialylation and fucosylation in cell migration.

\section{RNA isolation and gene expression}

RNA isolation and gene expression were performed using a modified protocol based on a previously described method (Mohd Isa et al., 2018). Briefly, cells were washed thoroughly with PBS before $1 \mathrm{~mL}$ TRIzol ${ }^{\circledR}$ was added. Scraping was performed using a pipette tip and the TRIzol ${ }^{\circledR}$ solution was transferred to a $2 \mathrm{~mL}$ microcentrifuge Eppendorf tube. Samples in TRIzol ${ }^{\circledR}$ were centrifuged at 1,200 $\times g$ for 5 min at $4{ }^{\circ} \mathrm{C}$ and the cellular debris was discarded. The clear supernatant was transferred to a clean tube and $200 \mu \mathrm{L}$ chloroform was added per $1 \mathrm{~mL} \mathrm{TRIzol}{ }^{\circledR}$ solution, mixed for $15 \mathrm{~s}$ and incubated at room temperature for $2 \mathrm{~min}$. The mixture was centrifuged at $4{ }^{\circ} \mathrm{C}$ for $15 \mathrm{~min}$ and the colourless supernatant that formed on the top of the mixture (containing RNA) was transferred to a new tube. This was mixed with an equal volume of $70 \%$ molecular grade ethyl alcohol. The mixture was transferred to a Qiagen RNeasy Mini column and centrifuged at $16,000 \times g$ for $15 \mathrm{~s}$; after that, the flow through was discarded. RNA bound to the column was washed with $700 \mu \mathrm{L}$ of RW1 buffer and $15 \mathrm{~s}$ centrifugation at 16,000 $\times g$. Next, $500 \mu \mathrm{L}$ of RPE buffer was added to the column, followed by $15 \mathrm{~s}$ centrifugation at $16,000 \times g$. Then, a further $500 \mu \mathrm{L}$ of RPE buffer was added and centrifugation was performed for 2 min. RNase-free water $(30 \mu \mathrm{L})$ was added and the mixture was centrifuged at $16,000 \times g$ for $1 \mathrm{~min}$ to collect RNA in a new collection tube. RNA concentration was determined using a

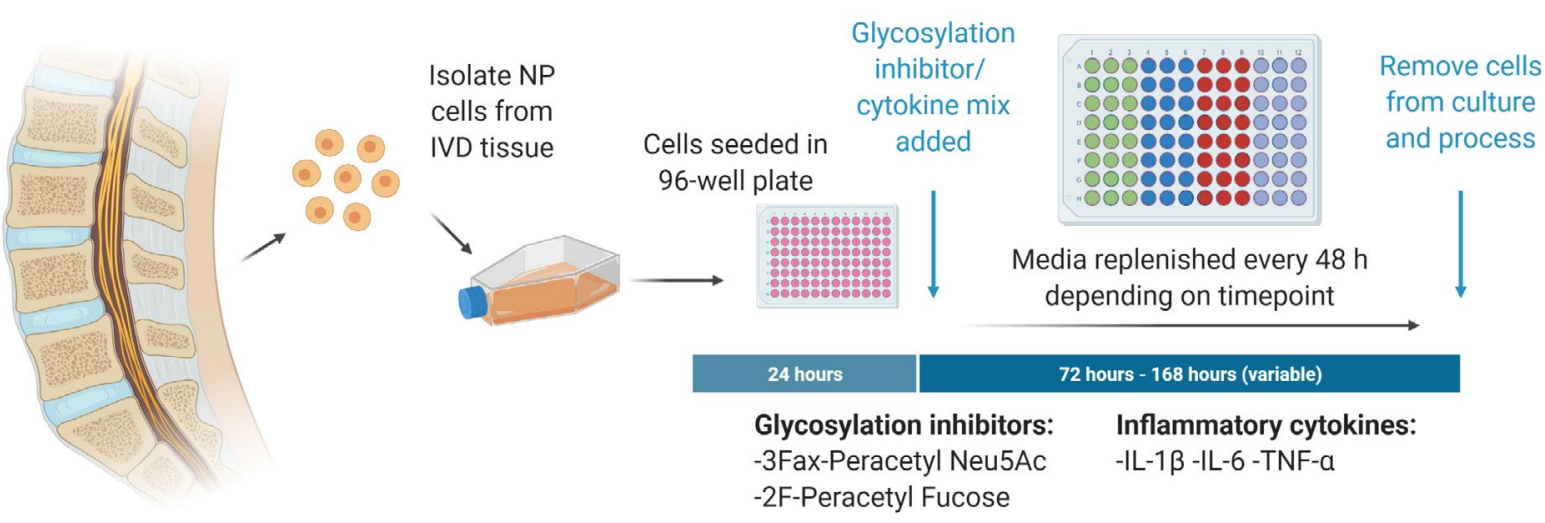

Sialylation inhibition in Golgi apparatus
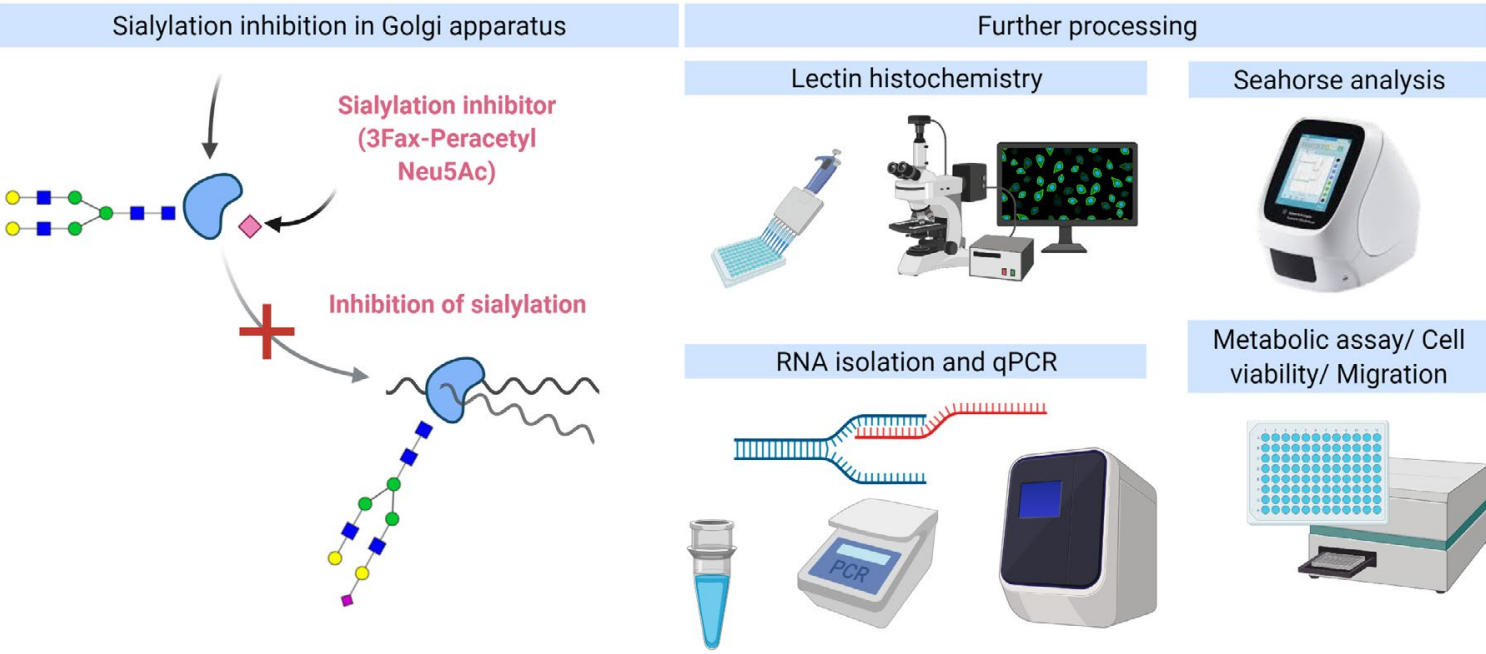

Metabolic assay/ Cell viability/ Migration

Fig. 1. Overview of experimental design of in vitro assessment of human NP cells. 
NanoDrop ${ }^{\mathrm{TM}}$ spectrophotometer (Thermo Scientific). Reverse transcription was performed using qScript cDNA SuperMix ${ }^{\mathrm{TM}}$ following the manufacturer's instructions. cDNA template was mixed with SYBR Green master mix as well as forward and reverse primers (COL1, COL2 and 18S; Table 3) to obtain a final reaction mixture. $\mathrm{qPCR}$ was performed using the StepOnePlus ${ }^{\mathrm{TM}}$ and gene expression was calculated as $\Delta \Delta \mathrm{Ct}$.

\section{Mitochondria function by Seahorse analysis}

The Seahorse XFe24 Analyzer (Agilent) was used to continuously monitor OCR and ECAR as per manufacturer's instructions. $3 \mathrm{~d}$ before the experiment, 20,000 cells/well were seeded in an 8 -well XFp cell culture plate in $\alpha$-MEM medium supplemented with $10 \%$ foetal bovine serum, $1 \% \mathrm{P} / \mathrm{S}$ and cultivated at $37^{\circ} \mathrm{C}$ in a humidified atmosphere and $5 \% \mathrm{CO}_{2}$ with IL-1 $\beta / \mathrm{IL}-6 / \mathrm{TNF}-\alpha(10 \mathrm{ng} / \mathrm{mL})$ or Neu5Ac-inhib or a combination of IL-1 $\beta /$ IL-6/TNF- $\alpha$ $(10 \mathrm{ng} / \mathrm{mL})$ and Neu5Ac-inhib. At least one well in each assay was used as an internal control. $1 \mathrm{~d}$ before the experiment, $1 \mathrm{~mL}$ of $\mathrm{XF}$ calibrator was added to each well of the $\mathrm{XF}$ cartridge and incubated overnight at $37{ }^{\circ} \mathrm{C}$ and $0 \% \mathrm{CO}_{2}$ in a humidified atmosphere. $30 \mathrm{~min}$ before the experiment, cells were washed with PBS and $625 \mu \mathrm{L}$ of respective $\mathrm{XF}$ assay medium supplemented with $10 \mathrm{mmol} / \mathrm{L}$ glucose, $1 \mathrm{mmol} / \mathrm{L}$ pyruvate and $2 \mathrm{mmol} / \mathrm{L}$ L-glutamine $(\mathrm{pH}$ adjusted to 7.4) was added per well and incubated for $30 \mathrm{~min}$ at $37^{\circ} \mathrm{C}$ and $0 \% \mathrm{CO}_{2}$ in a humidified atmosphere. After 15 min equilibration time, OCR and ECAR were accessed every $8.5 \mathrm{~min}, 4$ consecutive times after the addition of the respective compounds. The different compounds (oligomycin, FCCP, rotenone $+\operatorname{antimycin} \mathrm{A}$ ) were added to the injection ports of the $X F$ cartridge in a $10 \times$ final concentration and diluted prior the experiment in XF assay medium. Protein concentration was not normalised since a previous investigation (Thompson et al., 1990) demonstrated no effect on cell survival and proliferation rate under these conditions.

\section{Expression of catabolic enzymes by ELISA}

Cells were cultured for $72 \mathrm{~h}$ with IL-1 $\beta / \mathrm{IL}-6 / \mathrm{TNF}-\alpha$ and co-incubated with either Neu5Ac-inhib or Fucose-inhib. Medium was collected and centrifuged at 2,000 $\times g$ for $10 \mathrm{~min}$ to remove debris. Supernatant was removed and total protein collected. Samples were analysed using an MMP-13/ADAMTS-4 ELISA as per the manufacturer's instructions. The plate was prepared using appropriate lyophilised recombinant protein standards and fluorescence detection based on electrochemiluminescence was performed using the Varioskan Flash ${ }^{\mathrm{TM}}$ (Thermo Fisher Scientific) set at an OD of $450 \mathrm{~nm}$. A standard curve was plotted based on the ladder of standard concentrations and sample absorbance measurements were plotted against this to determine the absolute quantity of MMP-13/ ADAMTS-4 in the medium. Concentration values obtained were normalised to protein expression determined by BCA assay. Briefly, BCA assay was performed by pipetting $25 \mu \mathrm{L}$ standards and sample replicates into microplate wells. $200 \mu \mathrm{L}$ of working reagent was added to each well and mixed on a plate shaker for $30 \mathrm{~s}$. The plate was covered and incubated for $30 \mathrm{~min}$ at $37^{\circ} \mathrm{C}$. The plate was allowed to cool to room temperature before measuring the absorbance at $562 \mathrm{~nm}$ using a plate reader (Varioskan Flash ${ }^{\mathrm{TM}}$, Thermo Fisher Scientific).

\section{Statistical analysis}

Graphs and figures were created using GraphPad Software. Statistical differences in lectin histochemical quantification were analysed by GraphPad Software. One-way (Kruskal-Wallis) or two-way ANOVA were performed where appropriate followed by Tukey's post-hoc test. Mean and SEM were calculated for all groups. All error bars indicate SEM.

\section{Results}

\section{Altered glycosylation motif expression in degeneration}

Lectin histochemical analysis of IVD tissues revealed significant changes in the expression of accessible glycosylation motifs (Fig. 2). Foetal tissues showed the highest intensity of staining. The extracellular structure (lamellar arrangement in the AF) was easily observed, with high cellularity through both tissue types, AF and NP. Con A (binding/selective for $\alpha$-linked mannose) had little binding specificity for the ECM structures, showing intense staining in the intra/peri-cellular glycome. UEA-I (binding $\alpha-1,2 / 3$ fucose), similarly, lightly stained the ECM (Fig. 2b), while all other lectins (SNA, $\alpha-2,6$ sialylation; MAA, $\alpha-2,3$ sialylation; WGA, $\alpha-2,3 / 6$ sialylation) produced strong ECM staining throughout all tissue samples (Fig. 2c-e). Thompson grade III/IV (Thompson et al., 1990) tissue showed staining for all lectins. All lectins stained strongly in the ECM structures except Con A (Fig. 2a). The structure of the AF appeared completely disorganised with decreased cellularity. The NP also had decreased cellularity and granulomatous type structures were observed in the tissue. A granular pattern of staining was observed for Con A.

\section{Oligo-mannose}

Con A had little binding specificity for the ECM structures in foetal tissue, showing strong staining in the intra/peri-cellular glycome, while in diseased tissue grade III and IV there was a higher intensity of uniform ECM staining in the AF, with granular patterns also observed in both AF and NP (Fig. 2a). The volume fraction of positive staining in the NP and AF tissue was larger in degeneration and distribution of staining was visibly changed. This correlated with the altered oligomannose expression characterised by UPLC-MS. Con A lectin binds to oligomannose glycans and an increase in the expression of 
oligomannose structures is typically regarded as a progenitor cell marker (Hamouda et al., 2013).

\section{Sialylation}

$M A A$

High intensity staining with MAA was observed uniformly across the ECM in both AF and NP, with a sharp demarcation observed in the NP (Fig. 2d). The degenerated samples stained differently from the foetal tissue due to altered morphology: the ECM of the AF was disorganised, showed sharp demarcations and appeared more friable than foetal AF. The NP presented a granulomatous cluster of cells and granular staining in the ECM with strong peri- cellular staining. There was more binding of MAA in the NP of degenerated tissue when compared to healthy foetal tissue. This was consistent with a study by Mohd Isa et al. (2018) correlating an increase in sialylation with tissue inflammation.

\section{WGA}

Very high intensity staining was observed with WGA (Fig. 2e). The positive staining was restricted to the AF fibres, which reflected the lamellar arrangement of the tissue. Degenerated tissue had an intense AF staining, demonstrating a disorganised pattern of ECM structures. The NP was stained weakly, with a possible granulomatous structure observed.

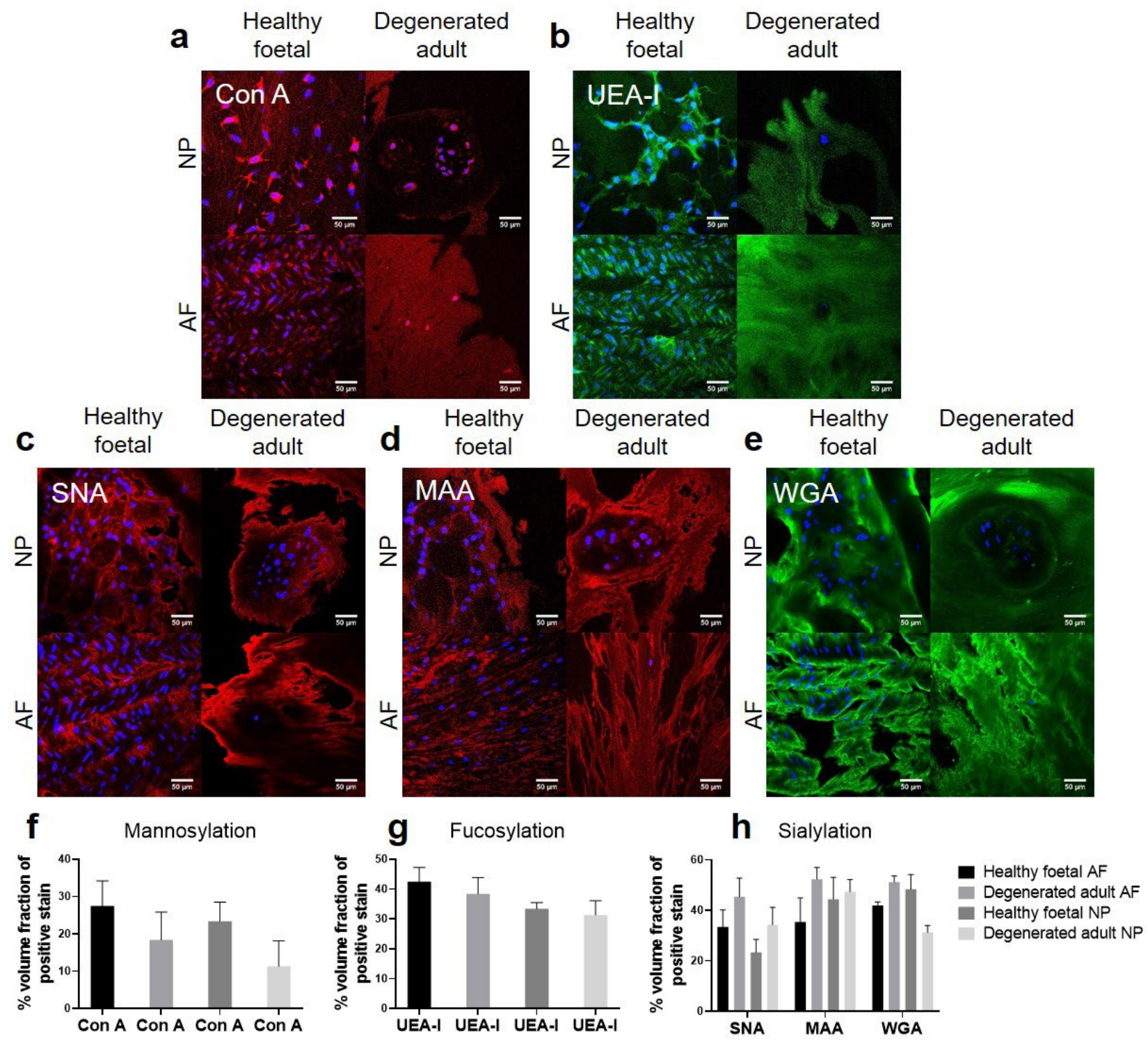

Fig. 2. The glycosignatures of healthy foetal and degenerated adult IVD tissue were different. (a) Mannosylation, (b) fucosylation and (c-e) sialylation motif expression in healthy foetal tissue and degenerated adult tissue using lectin histochemistry. Graphs indicate a change in the \% volume fraction of lectin binding sites in degeneration relative to healthy IVD. Confocal images of mannose were detected by Con A, $\alpha-(1-2 / 3)$-fucosylation by UEA-I and $\alpha-(2,6)-$ linked sialic acid, $\alpha-(2,3)$ sialylated galactose, $N$-acetylglucosamine and sialic acid by SNA, MAA and WGA, respectively. (f) Mannosylation and (g) fucosylation trended towards a decrease in expression. (h) $\alpha-(2,6)-$ linked sialylation was increased in degenerated tissues while total sialylation trended towards an increase. Two-way ANOVA with Tukey's post-hoc test, data presented as mean \pm SEM. Scale bar: $50 \mu \mathrm{m}$. 


\section{SNA}

Staining for SNA-binding sites in the AF of the foetus reflected the lamellar arrangement of the tissue (Fig. 2c). SNA staining in the foetal NP demonstrated a high intensity peri-cellular pattern, with low intensity staining throughout the ECM. Degenerated tissue showed high intensity staining of the ECM in the $\mathrm{AF}$, although a lamellar formation was not observed. Low cellularity and deranged staining pattern were apparent. The AF and NP were highly stained, more than foetal samples, in the degenerated tissues, where higher levels of sialylation were observed. This was in line with a previous demonstration of high levels of sialylation in inflamed or degenerated human chondrocytes (Pabst et al., 2010; Toegel et al., 2013).

\section{Glycosignature of NP cells}

The glycosignatures of healthy and degenerated NP cells were characterised by various lectins specific for a spectrum of glycosylation motifs (Fig. 3a). SNA ( $\alpha-2,6$ sialylation), AAL ( $\alpha-1,6$ fucosylation) and GS-I-B4 ( $\beta-1,4$ galactosylation) were all significantly increased in degenerated cells, while binding capacity of MAA ( $\alpha-2,3$ sialylation), UEA-I ( $\alpha-1,2 / 3$ fucosylation) and Con A ( $\alpha-1,6$ mannosylation) was significantly decreased $(p<0.05)$. Lectin specificity and preferential binding to glycosylation motifs are based upon motif of highest affinity, as described in the literature (Haab, 2012; Haab and Klamer, 2020).

\section{Cell viability and inhibition of global fucosylation and sialylation}

The stability of glycosylation motif expression in NP cells across passaging and expansion was investigated up to passage 7 (Fig. 3c,d). The binding intensity of SNA, AAL and Con A did not change significantly across passaging. NP cells are generally considered to lose their phenotype after passage 6 and are only used experimentally within these limits (Richardson et al., 2017).

NP cells incubated with specific global inhibitors of glycosylation, Neu5Ac-inhib and Fucose-inhib, underwent analysis for metabolic activity and overall cell survival. There was no significant change in the metabolic activity as detected by the fluorimetric readout of alamarBlue ${ }^{\circledR}$ assay (Fig. 5a) nor was there a decrease in cell survival when NP cells were incubated with varying concentrations of inhibitor for $10 \mathrm{~d}$ (Fig. 5b).

After $10 \mathrm{~d}$, these cells underwent lectin histochemical analysis to determine the efficacy of inhibition. Sialylation decreased by $43.55 \%(p<0.001)$ a

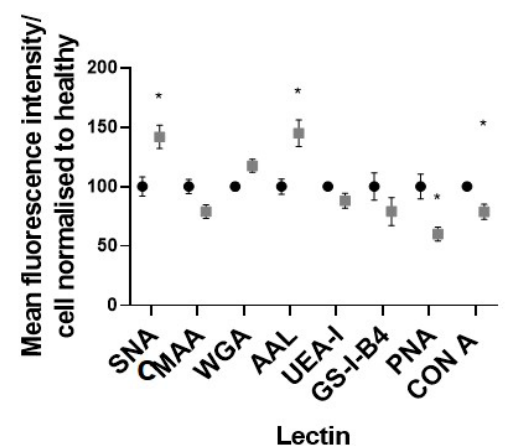

C

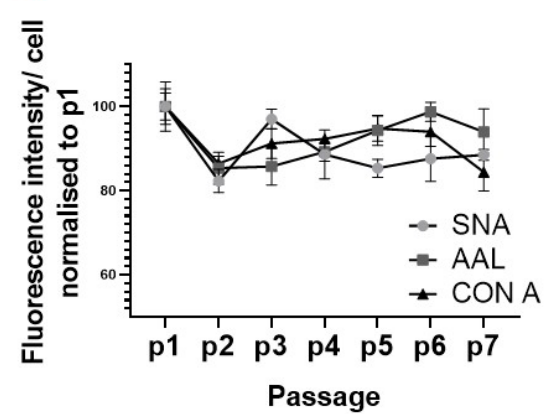

b

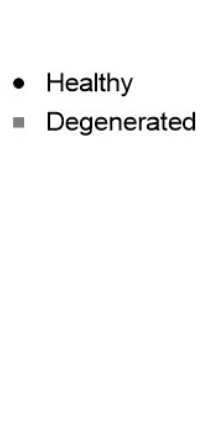

d

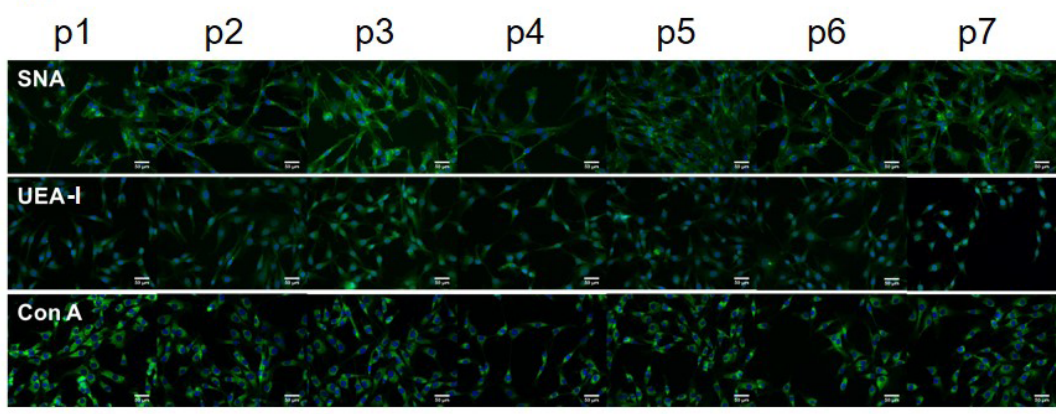

Fig. 3. Both degenerated and inflamed NP cells expressed similar glycosignatures characterised by increased sialylation and fucosylation as well as decreased mannosylation. (a) Altered glycosignature of human NP cells isolated from healthy and degenerated IVDs. Lectin histochemical characterisation revealed increased binding of SNA, AAL and Con A in degenerated NP cells that were specific for sialylation, fucosylation and mannosylation, respectively $(p<0.05)$. (b) Glycosignature of human healthy NP cells induced with inflammatory cytokines. The altered binding specificity of SNA and AAL was increased on day 3 in the cytokine-treated group. (c,d) Stability of glycosylation motif expression in human NP cells through passaging. There was no significant difference detected in sialylation, fucosylation and mannosylation from passage 1 (p1) to passage 7 (p7) as detected by SNA, AAL and Con A, respectively. $n=3$. Scale bar: $50 \mu \mathrm{m}$. Two-way ANOVA with Tukey's post-hoc test, data presented as mean \pm SEM. 
as shown by SNA staining, where no change was observed for MAA staining (Fig. 5c,d). No further inhibition of sialylation was observed with inhibitor concentration higher than $300 \mu \mathrm{mol} / \mathrm{L}$ (Fig. 5g). Fig. $5 c$ depicts the confocal images of NP cells with and without Neu5Ac-inhib after $10 \mathrm{~d}$, where no change in cellular morphology was observed. No specific pattern of sialylation was altered; however, there was a global decrease in SNA-binding $(p<0.001)$.

A similar trend was observed with the Fucoseinhib, with a decrease in core fucosylation, detected by AAL, of $73.37 \%(p<0.001)$ (Fig. 5f). The most significant decrease was observed at $300 \mu \mathrm{mol} / \mathrm{L}$ of inhibitor, which did not decrease further with higher concentrations of Fucose-inhib (Fig. 5h). This was in contrast with UEA-I binding, which detected no significant change across inhibitor concentrations. Fig. 5e demonstrates the change in AAL and UEA-I binding in cells inhibited with Fucose-inhib. The confocal images showed an apparent change in cell morphology towards a more elongated phenotype in inhibitor-treated cells. UEA-I lectin binding pattern was also altered, with focal streaky intensity observed. However, overall UEA-I intensity was unchanged.

\section{Optimisation of in vitro inflammatory model of NP cells}

Initially, the glycosylation profile of NP cells was investigated when stimulated with individual cytokines (Fig. 4). IL-1 $\beta$ had the most prominent effect after $3 \mathrm{~d}$, increasing sialylation (measured by
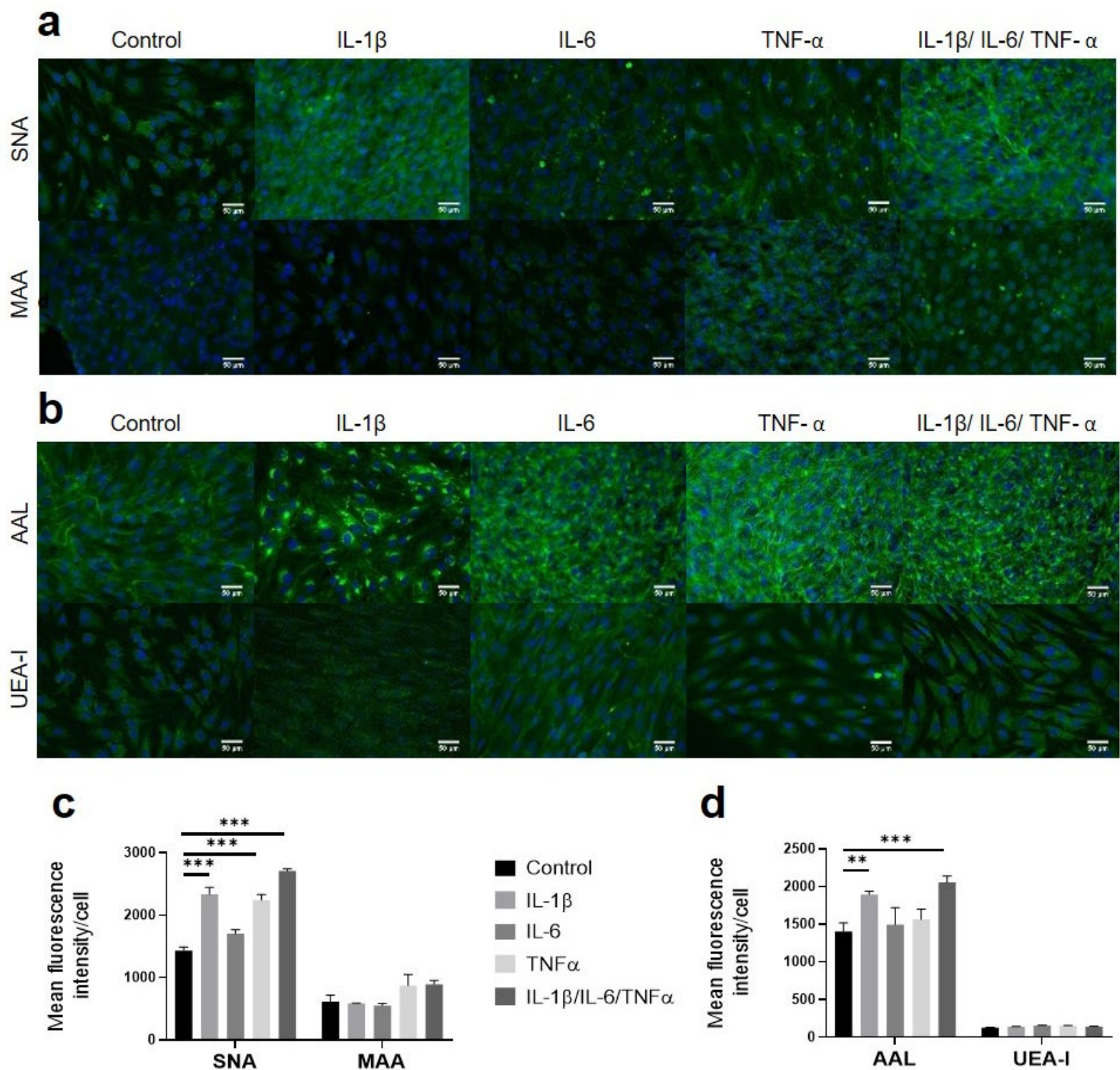

Fig. 4. Cytokine-mediated inflammation induced hyperglycosylation in NP cells. (a) Sialylation response to cytokine-induced inflammation measured by MAA and SNA binding. (c) IL-1 $\beta$ had the most prominent effect after $3 \mathrm{~d}$, increasing sialylation by $62 \%$, whereas TNF- $\alpha$ and IL- 6 increased sialylation by $56 \%$ and $19 \%$, respectively. The cytokine combination increased sialylation by $89 \%$. (b) Fucosylation response to cytokine-induced inflammation measured by AAL and UEA-I binding. (d) IL-1 $\beta$ induced the largest fucosylation response of all the cytokines (35\% increase) followed by TNF- $\alpha$ and IL- $6,11 \%$ and $6 \%$ increases, respectively. A combination of cytokines caused a $46 \%$ increase in core fucosylation. $n=3$. Scale bar: $50 \mu \mathrm{m}$. One-way ANOVA with Tukey's post-hoc test, data presented as mean \pm SEM. 
SNA) by $62.86 \%(p<0.001)$, whereas TNF- $\alpha$ and IL-6 increased sialylation by $56.41 \%(p<0.001)$ and $18.90 \%(p=0.1999)$, respectively (Fig. 4a,c). The greatest response, as measured by SNA-binding, was observed with a combination of all cytokines, with a significant total increase in sialylation expression, as detected by SNA, of $89.11 \%(p<0.001)$. MAA binding expression demonstrated marginally increased staining with TNF- $\alpha$ and cytokine combination, despite not being statistically significant $(p=0.1816)$.

Similar results were observed measuring fucosylation expression under cytokine stimulation, as a hyperfucosylated state emerged (Fig. 4d). IL$1 \beta$ caused the most significant hyperfucosylation response (measured by AAL) of all individual cytokines $(35.03 \%$ increase, $p<0.01)$ followed by TNF- $\alpha$ and IL-6, $11.44 \%(p=0.7574)$ and $6.46 \%$ $(p=0.9616)$, respectively. A combination of cytokines caused a $46.45 \%$ increase in core fucosylation, indicating an additive effect $(p<0.0001)$. No trend in fucosylation modulation was observed with UEA-I binding. This cytokine combination was used in all further investigations as it reliably reproduced the hypersialylated and hyperfucosylated glycophenotype observed in degenerated cells and tissues.

The glycosylation motifs of NP cells when stimulated with a cytokine mix were examined by lectin cytochemistry (Fig. 3b). The most prominent alteration in the glycosylation pattern was observed on day 3 vs. day 1 and 7 . There was a significant increase in binding of SNA $(45.57 \%, p<0.01)$, AAL $(43.12 \%, p<0.05)$ and Con A $(35.76 \%, p<0.05)$ on day 3 . The binding pattern of lectins on day 3 best reflected the glycosylation pattern of degenerated NP cells, both demonstrating increased $\alpha-(2,6)$ sialylation and $\alpha-(1,6)$ fucosylation detected by SNA and AAL, respectively.

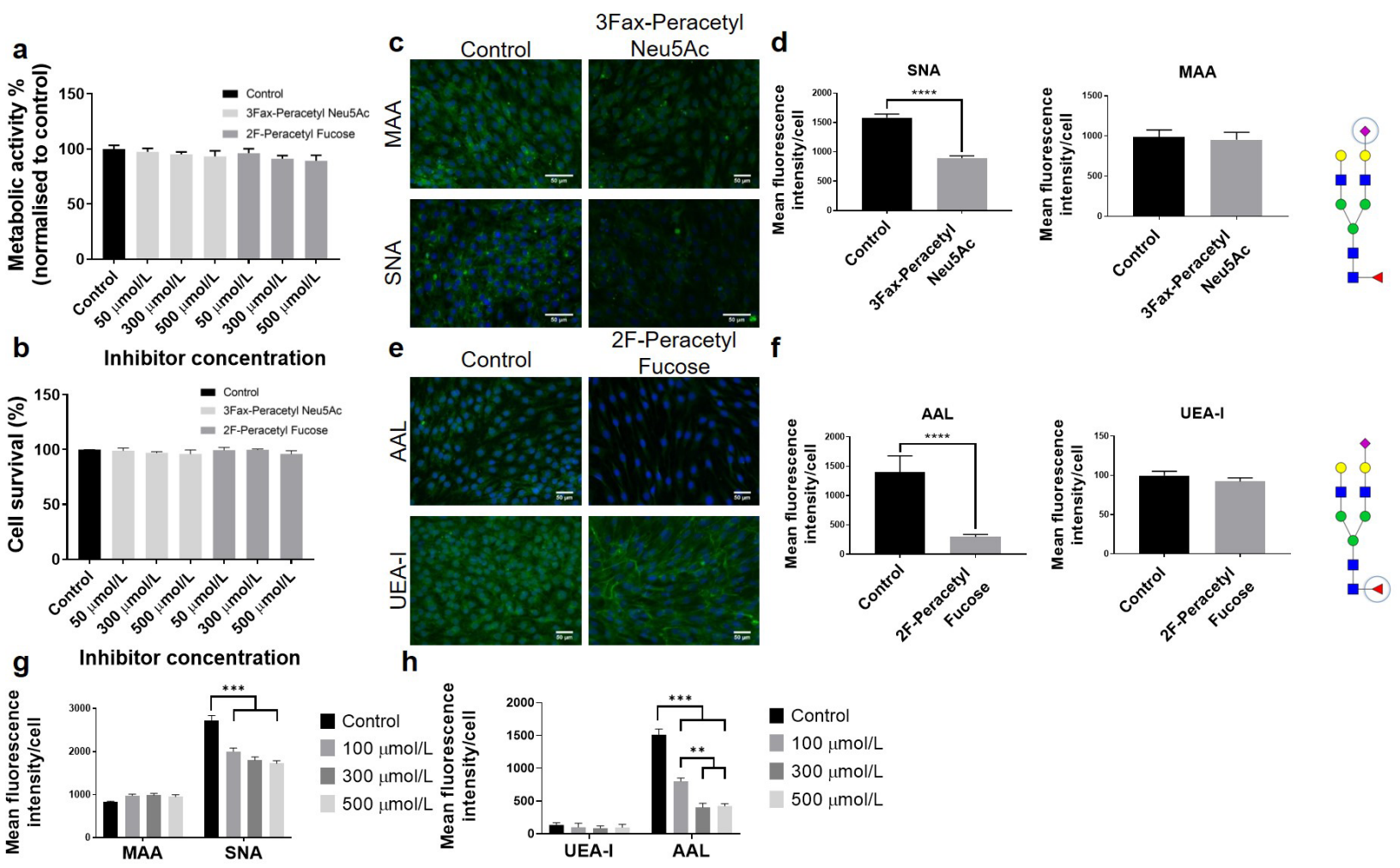

Fig. 5. Small molecule glycosylation inhibitors were non-cytotoxic and efficient inhibitors of sialylation and fucosylation. Viability study of NP cells after treatment with varying concentrations of 3Fax-Peracetyl Neu5AC and 2F-Peracetyl-Fucose. (a) There was no significant difference observed in metabolic activity across all groups as measured by alamarBlue ${ }^{\mathrm{TM}}$ assay. (b) Live/dead assay determined total cell survival after treatment. All concentrations of inhibitor maintained $>95 \%$ cell survival after $10 \mathrm{~d}$ co-incubation with no significant difference across groups. (c,d) Optimised inhibition of sialylation in NP cells by 3Fax-Peracetyl Neu5Ac. Confocal images showed no change in cell morphology in treatment $v$ s. control. $\alpha-(2,6)$ sialylation (SNA) was significantly decreased $(p<0.001)$ by $\sim 40 \%$ while $\alpha-(2,3)$ sialylation (MAA) expression remained unaltered. (e,f) Optimised inhibition of fucosylation in NP cells by 2F-Peracetyl-Fucose demonstrated no change in cell morphology in treatment vs. control. $\alpha-(1,6)$ fucosylation (AAL) was significantly decreased $(p<0.001)$ by $\sim 70 \%$ while $\alpha-(1,3)$ fucosylation (UEA-I) remained unaltered. (g,h) Expression of glycosylation modifications after treatment with global inhibitors of glycosylation. Sialylation fluorescence intensity as detected by MAA- $\alpha-(2,3)$ and SNA- $\alpha-(2,6)$ lectins. $\alpha-(2,6)$ sialylation was reduced significantly by $\sim 40 \%$ at a concentration of $300 \mu \mathrm{mol} / \mathrm{L}$ of 3Fax-Peracetyl Neu5Ac after $10 \mathrm{~d}$ of treatment. Core fucosylation $\alpha-(1,6)$ expression as measured by AAL decreased with increased concentration of 2F-Peracetyl-Fucose to $~ 70 \%$ reduction at $300 \mu \mathrm{mol} / \mathrm{L}$ of inhibitor. $n=3$. One-way ANOVA with Tukey's post-hoc test, data presented as mean \pm SEM. 
Expression of ECM proteins in healthy and degenerated NP cells was characterised by qPCR (Fig. 7a). COL1 expression was the same in both healthy and degenerated cells, while COL2 and ACAN expression were reduced of $99.78 \%(p<0.001)$ and $67.54 \%(p<0.01)$, respectively, in degenerated NP cells. Expression of all measured ECM components (COL1, COL2, ACAN) was reduced in healthy cells induced with cytokines for $3 \mathrm{~d}(p<0.05)$. COL1 expression was diminished in degenerated cells under cytokine stimulation $(p<0.05)$; however, no noticeable reduction was recorded in the already reduced COL2 and ACAN expression.

\section{Glycosylation inhibitors effectively regulated} sialylation and fucosylation in an in vitro model of inflammation

The glycomic response of NP cells was measured with respect to inflammation in both healthy and degenerated human NP cells (Fig. 6). The baseline sialylation of degenerated NP cells was more significant than healthy NP cells, as previously characterised $(p<0.01)$. A cytokine cocktail increased sialylation expression in both healthy and degenerated cells of $80.40 \%$ and $10.07 \%$, respectively. This increase was consequently inhibited by Neu5Acinhib, retaining the sialylation motif expression at healthy baseline levels in healthy cells, $5.54 \%$ difference $v s$. baseline $(p=0.9587), 41.49 \%$ decrease vs. cytokine stimulation $(p<0.0001)$ (Fig. 6a,c). In degenerated cells treated with Neu5Ac-inhib, the sialylation expression was further reduced to the baseline of healthy NP cells, $18.54 \%$ reduction vs.

a $\begin{array}{lll}\text { Control 3Fax-Peracetyl IL-1 } 3 / \text { /L-6/TNF- } \alpha & \text { Neu5Ac/L-1 } 1 \beta /\end{array}$ Neu5Ac/lL-1

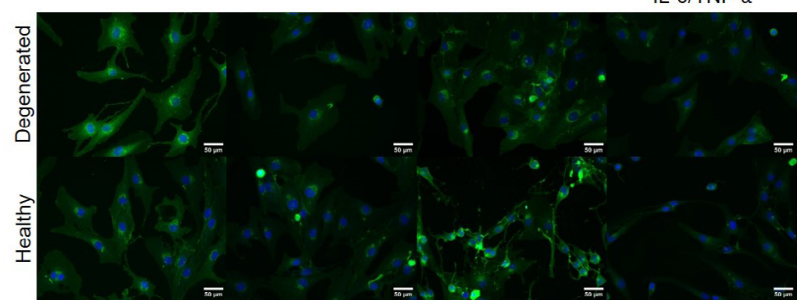

C

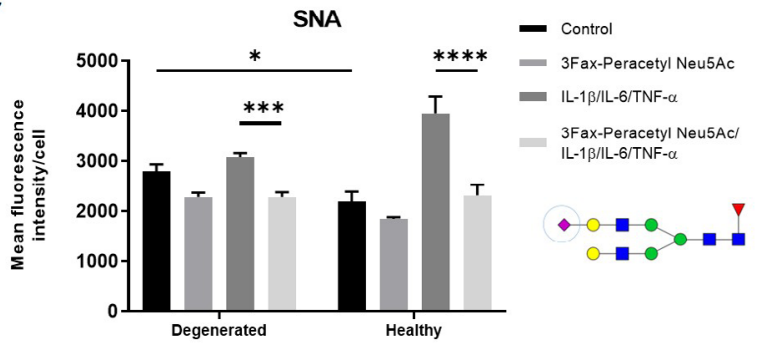

baseline $(p=0.18)$ and $23.00 \%$ reduction $v$ s. cytokine stimulation $(p<0.05)$.

Inhibition of hyperfucosylation in cytokineinduced inflammation treated with Fucose-inhib was assessed by AAL staining (Fig. 6b,d). Initial baseline fucosylation in degenerated NP cells was lower than healthy NP cells $(p<0.05)$. Binding of AAL was increased in the IL-1 $\beta / \mathrm{IL}-6 / \mathrm{TNF}-\alpha$ group after $72 \mathrm{~h}$ $(p<0.001)$. This hyperfucosylation response was inhibited by Fucose-inhib in both degenerated and healthy NP cells $(p<0.001)$.

\section{Glycosylation inhibitors downregulated collagen expression}

COL1 and COL2 expression was measured by qPCR, where mRNA was extracted from healthy and inflamed NP cells with or without glycosylation inhibitors after $3 \mathrm{~d}$ of cytokine/inhibitor stimulation. Fig. $\mathbf{7 b} \mathbf{b} \mathbf{d}$ indicates the initial expression of COL1/2 in NP cells normalised to $18 \mathrm{~S}$ ribosomal subunit. Cytokine stimulation reduced COL2 significantly $(p<0.01)$. Neu5Ac-inhib enhanced COL2 expression $(p<0.01)$, while Fucose-inhib had no effect. Neu5Acinhib had no effect on modulation of collagen expression in cytokine stimulation; however, Fucoseinhib further reduced COL1 and COL2 expression in cytokine stimulation $(p<0.001)$. While Neu5Ac-inhib did not influence total collagen RNA expression, the COL2 : COL1 ratio, an important marker of NP cell phenotype (Clouet et al., 2009), was maintained under cytokine-induced inflammation (Fig. 7c). Fucoseinhib had no effect on COL2 expression and further diminished the COL2 : COL1 ratio (Fig. 7e).

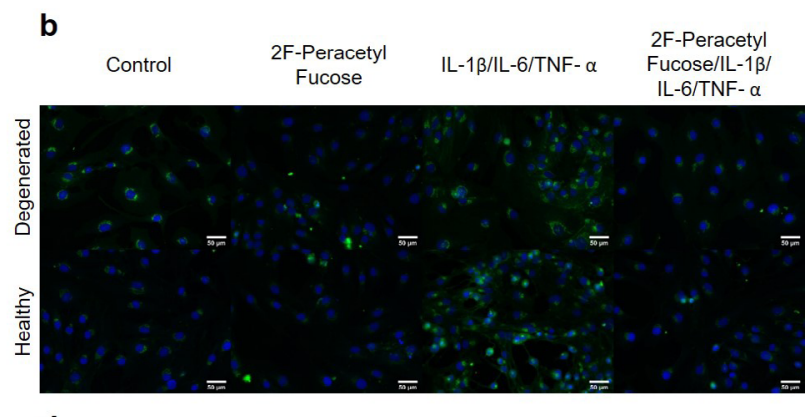

d

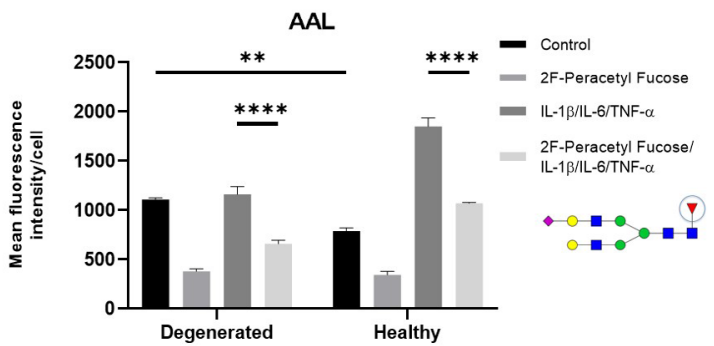

Fig. 6. Small-molecule inhibitors of glycosylation inhibited cytokine-mediated hyperglycosylation. (a) Sialylation response to cytokine-induced inflammation measured by MAA and SNA binding. (c) IL-1 $\beta$ had the most prominent effect after $3 \mathrm{~d}$, increasing sialylation by $62 \%$, whereas TNF- $\alpha$ and IL- 6 increased sialylation by $56 \%$ and $19 \%$, respectively. Cytokine combination increased sialylation by $89 \%$. (b) Fucosylation response to cytokine-induced inflammation measured by AAL and UEA-I binding. (d) IL-1 $\beta$ produced the largest fucosylation response of all the cytokines (35\% increase) followed by TNF- $\alpha$ and IL-6, $11 \%$ and $6 \%$ increases, respectively. A combination of cytokines caused a $46 \%$ increase in core fucosylation. $n=3$. Scale bar: $50 \mu \mathrm{m}$. One-way ANOVA with Tukey's post-hoc test, data presented as mean \pm SEM. 
MMP-13 synthesis was inhibited by glycosylation inhibition

MMP-13 and ADAMTS-4, potent collagenase/ aggrecanase degrading enzymes (Fearing et al., 2018), were upregulated in cytokine-stimulated NP cells, as measured by ELISA normalised to protein expression $(p<0.01)$ (Fig. 8). The release of MMP-13 and ADAMTS-4 was inhibited by Neu5Ac-inhib $(p<0.01)$ and tended to decrease with Fucose-inhib co-incubation ( $p=0.07, p=0.11$, respectively).

\section{Cell migration modulation}

Cell migration assays demonstrated the reduced mobility of inflamed NP cells. The calcein AM staining of live cells allowed for enhanced visualisation of NP cells in this gap closure assay (Fig. 9). At the $48 \mathrm{~h}$ time point, there were clear and significant differences across experimental groups. Neu5Ac-inhib restored the migration of inflamed NP cells (no migration observed) to within normal limits $(10.26 \pm 2.12 \%$ closure, $p=0.08$ ) and further increased baseline migration in non-inflamed cells $(25.23 \pm 2.91 \%$ closure vs. $18.00 \pm 1.47 \%$ closure, $p=0.10$ ) (Fig. 9a,c).

Fucose-inhib reduced cell migration across both inflamed and non-inflamed cells (Fig. 9b,d). This time point was recorded at $72 \mathrm{~h}$ as opposed to $48 \mathrm{~h}$ in which the previous assay was recorded. This disparity was used to illustrate the difference between inflamed cells and inflamed cells treated with Fucoseinhib, since no migration was observed at $48 \mathrm{~h}$. After $72 \mathrm{~h}, 71.02 \pm 0.55 \%$ gap closure occurred in the control group, while this was reduced in inflamed cells $(53.98 \pm 1.24 \% ; p<0.0001)$. When treated with Fucose-inhib, cell migration decreased in both control (71.02 $\pm 0.55 \%$ vs. $59.86 \pm 1.23 \%, p<0.001)$ and cytokine stimulation ( $53.98 \pm 1.24 \%$ vs. $42.95 \pm 0.60 \%$, $p<0.001)$ groups.

a
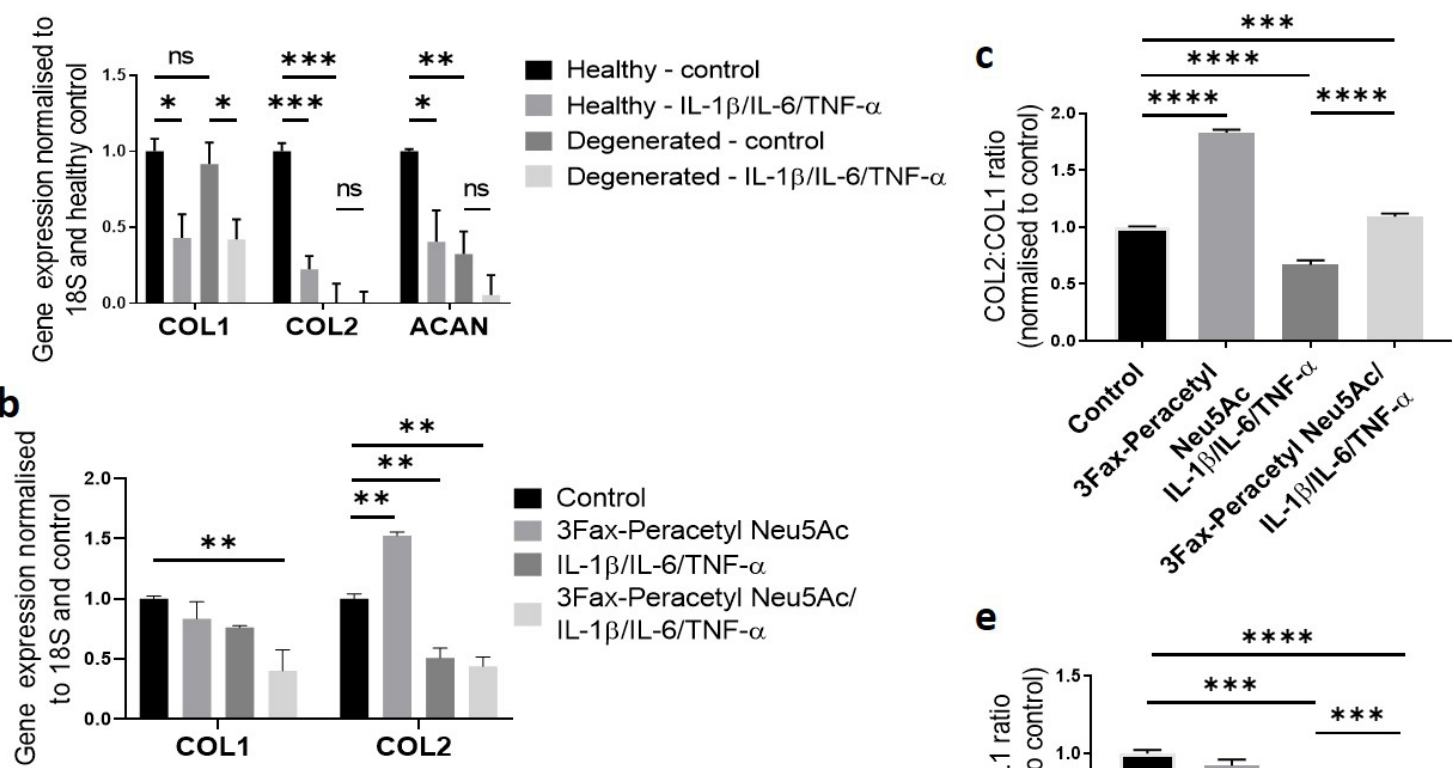

Control

3Fax-Peracetyl Neu5Ac

IL-1 $\beta /$ IL-6/TNF- $\alpha$

3Fax-Peracetyl Neu5Ac/

IL-1 $\beta / I L-6 / T N F-\alpha$

e

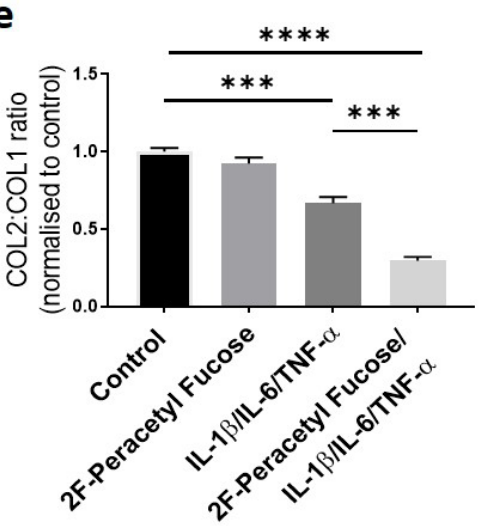

\section{d}

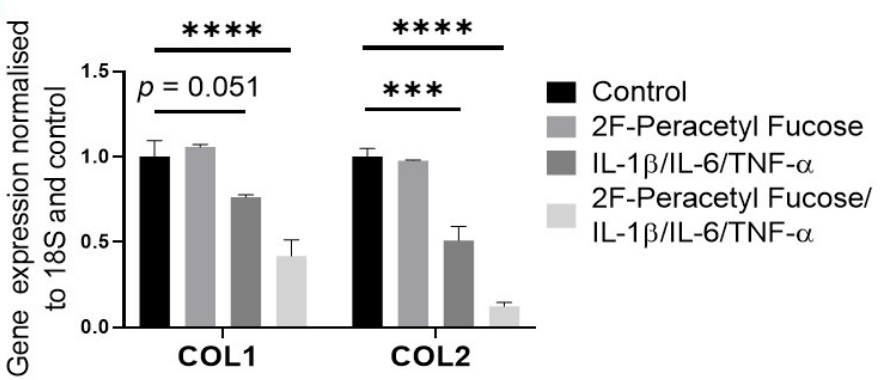

Fig. 7. $C O L$ and $A C A N$ expression was modulated by inflammatory signalling and glycosylation pathways. (a) Expression of ECM proteins in healthy and degenerated NP cells. COL1 expression was the same in both cell types while COL2 and ACAN were reduced in degenerated NP cells. Expression of all ECM proteins was reduced in cells induced with cytokines after $3 \mathrm{~d}$. (b) 3Fax-Peracetyl Neu5Ac treatment increased COL2 expression in non-inflamed cells $(p<0.01)$. No significant difference was seen in inflamed groups. (c) The ratio of COL2 : COL1 expression, a marker of NP cell phenotype, was maintained in 3FaxPeracetyl-treated cells, although total gene expression was decreased. (d) 2F-Peracetyl-Fucose had no effect on healthy NP cells and further reduced COL2 expression in inflamed NP cells. (e) COL2 : COL1 ratio was further lost in 2F-Peracetyl-Fucose-treated inflamed cells. Two-way ANOVA with Tukey's post-hoc test, data presented as mean \pm SEM. 


\section{Mitochondrial dysfunction in inflammation}

The effect of sialylation inhibition on inflamed NP cells was investigated by the Agilent Seahorse XFe24 Analyzer using the Mito Stress test ${ }^{\circledR}$ (Fig. 10). Mitochondrial physiology was investigated by measuring ECAR and OCR, critical indicators of mitochondrial function and respiratory capacity. NP cells showed a low basal mitochondrial oxygen consumption that was approximately $50 \%$ coupled to ATP production. Treatment with cytokine stimulation induced a significant increase in basal and maximal OCR (FCCP-treated, a potent uncoupler of mitochondrial oxidative phosphorylation) $(p<0.001)$ (Fig. 10a). The increase in basal and maximal OCR was inhibited by Neu5Ac-inhib $(p<0.001)$ (Fig. 10c). The residual OCR after oligomycin treatment indicated no difference in proton leak across groups. Altogether, these results indicated that the activation of the inflammatory pathways regulated mitochondrial respiratory function, altering glycolysis, ECAR and OCR in a glycosylation-dependent manner.

\section{Discussion}

The results of the initial lectin histochemical analysis were consistent with a previous glycosylation profiling in an injury rat-IVD model where higher levels of sialylation in injured discs were observed (Mohd Isa et al., 2018). Mohd Isa et al. (2018) showed that surgically induced IVD injury is associated with altered glyco-profile and degenerative changes in the disc, including neurotransmission, inflammation as well as an imbalance of catabolism and anabolism. The results of the rat-tail model study may also be validated by an ovine animal model of degeneration, showing similar findings as to glycosylation changes in aged degeneration (Collin et al., 2016). The study reported that specific spatial and temporal glycans patterns throughout maturity were observed and specific glyco-markers were identified, which allowed distinction between NP and AF tissues and cells. The present study showed similar trends in lectin binding in inflammation to the IVD model created from bovine tissue, demonstrating increases in sialylation, mannosylation and galactosylation when cells were stimulated with IL-1 $\beta$ (Srivastava et al., 2017).

The initial characterisation of human NP cells in situ in healthy and degenerated IVD tissues and after isolation revealed a previously characterised phenomenon of hypersialylation and hyperfucosylation in IVD tissues in inflammation and degeneration (Kazezian et al., 2017; Mohd Isa et al., 2018). The present was the first glycosignature obtained from human NP cells in the literature. The increased positive staining of SNA and AAL found in the present study indicated an increase in $\alpha-(2,6)$ sialylation and core fucosylation. These signatures were previously reported to be upregulated in chondrocytes and epithelial cells in response to inflammatory cytokines (Delmotte et al., 2002; Pabst et al., 2010). Cytokine-induced healthy NP cells produced a similar glycosylation profile to degenerated NP cells, characterised by increased SNA, WGA and AAL positive staining. The replication of this glycosignature gives further validation to the in vitro inflammatory model in relation to the glycomic response of NP cells in degeneration. The downstream regulation of glyco-enzymes and posttranslational modifications during protein synthesis and trafficking is highly complex, reflected by the varying responses to IL-1 $\beta$, IL- 6 and TNF- $\alpha$.

The NP phenotype is gradually lost through passaging and cells generally lose key markers beyond passage 5 (Benya et al., 1978; van den Akker et al., 2014). Therefore, it was crucial to consider the
I

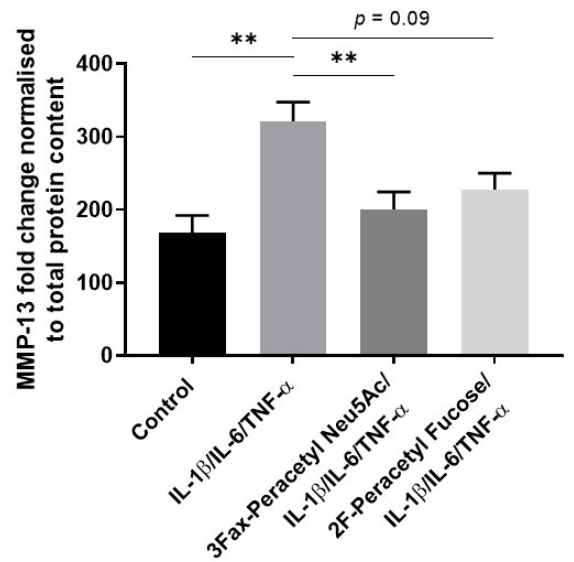

b

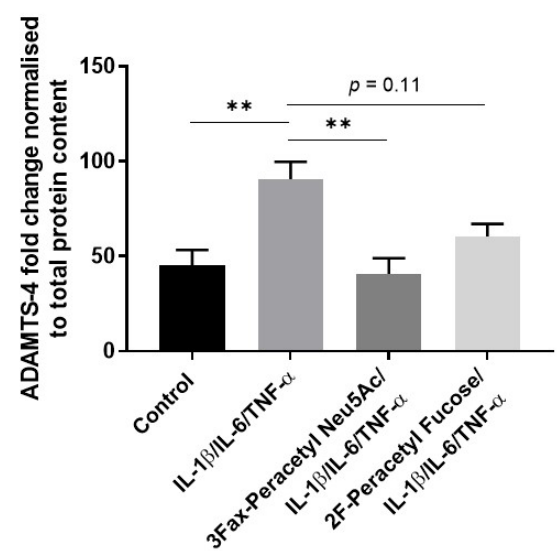

Fig. 8. Glycosylation regulated the expression of catabolic enzymes. Protein expression of (a) MMP-13 and (b) ADAMTS-4, as measured by ELISA, was decreased by glycosylation inhibition. $n=3$. MMP-13 and ADAMTS-4 expression increased by IL-1 $\beta / \mathrm{IL}-6 /$ TNF- $\alpha$. Both 3Fax-Peracetyl Neu5Ac and 2F-PeracetylFucose inhibited MMP-13 and ADAMTS-4 protein expression. One-way ANOVA, $p<0.05$. Data presented as mean \pm SEM. 
stability of the glycophenotype of the NP cell through passaging and expansion. The glycosignature remained stable through to passage 7 , indicating that glyco-enzyme activity was highly conserved through cell proliferation under stable conditions.

Small-molecule-inhibitors are very useful in biomedical applications for biomaterial functionalisation due to their relative stability and eases of delivery (Natoni et al., 2020). Neu5Acinhib and Fucose-inhib were investigated for their potential to modulate the glycome in vitro. It was initially confirmed that these molecules did not have a detrimental effect on cell metabolism and viability. The efficacy of inhibition was determined for each molecule and the most significant inhibition was achieved at $300 \mathrm{mmol} / \mathrm{L}$ as per the manufacturer's instructions. No specific pattern of sialylation was altered; however, there was a global decrease in SNAbinding positivity $(p<0.001)$, whereas no change in MAA binding was observed. This indicated an increased turnover and subsequent preferential inhibition in primarily $\alpha-(2,6)$ sialylation over $\alpha-(2,3)$ sialylation. The mean expression of fluorescence intensity of SNA was also much more significant than that of MAA, indicating a larger proportion of accessible $\alpha-(2,6)$ sialylation to $\alpha-(2,3)$ sialylation overall, assuming similar binding efficiencies and specificity of lectins.

Similar trends were seen in fucosylation inhibition, where AAL binding was significantly reduced after inhibition vs. UEA-I binding, which was unaffected. The change in UEA-I binding was indicative of ER stress, with bottlenecks in glycan synthesis due to the inhibition of core fucosylation, a crucial glycan modification for the activity of many proteins. However, this phenomenon needs further investigation.

Collagen is a glyco-modified protein whose degradation is altered by the level of glycosylation (Jürgensen et al., 2011). Therefore, synthesis and trafficking of collagen are influenced by glycosylation efficiency in the GA. The effect of cell glycosylation on collagen synthesis was investigated by PCR. It appears that sialylation inhibition promoted COL2 synthesis. However, this effect has not previously been investigated and the mechanism by which this process may be regulated is unknown. The prominent factor in this investigation was that Neu5Ac-inhib retained the NP cell phenotype in inflammation. However, sialylation inhibition was not sufficient
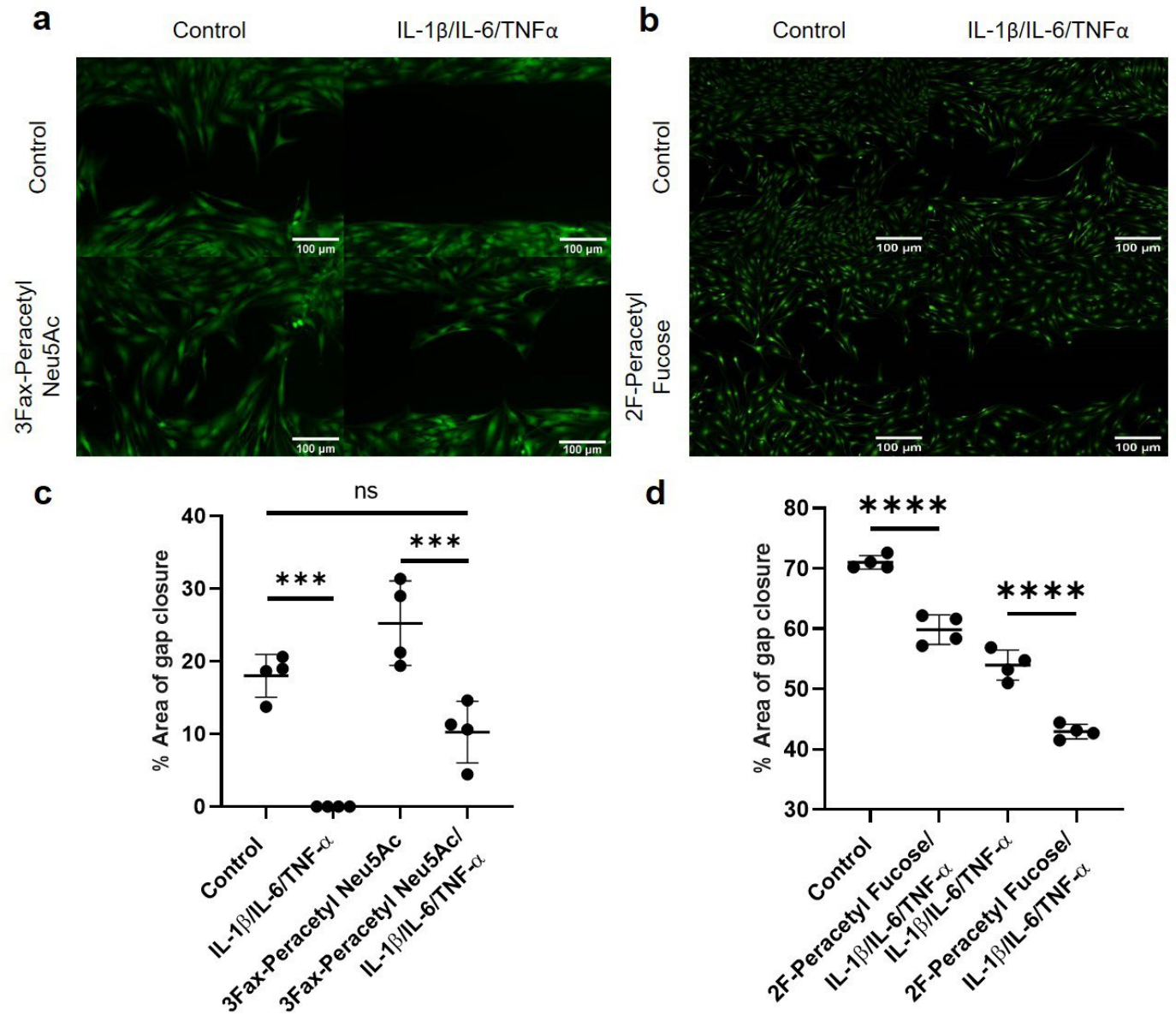

d

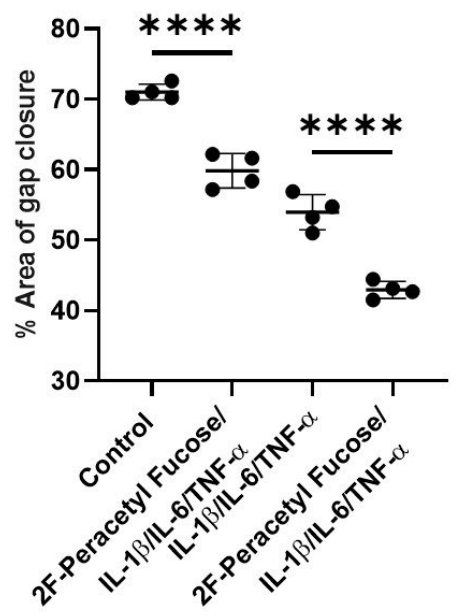

Fig. 9. Sialylation inhibited cell migration in inflammation while fucosylation was crucial for cell motility. $(a, c)$ Sialylation inhibition restored cell migration to inflamed NP cells in wound healing assay after $48 \mathrm{~h}$. Cell migration was increased in 3Fax-Peracetyl Neu5Ac-treated group versus inflamed group $(p<0.001)$. (b,d) Fucosylation inhibition further diminished cell migration in inflamed NP cells after 72 h. 2F-PeracetylFucose treatment further inhibited the decrease in cell migration in the inflamed group $(p<0.05) . n=4$. Scale bar: $50 \mu \mathrm{m}$. One-way ANOVA, $p>0.05$. Data presented as mean \pm SEM. 
to sustain overall COL1 and COL2 expression at a transcription level.

The monosaccharide synthesis pathways that are glycan precursors are intrinsically linked to metabolism (Ryczko et al., 2016). Also, the inflammatory cascade increases mitochondrial activity and dysfunction (López-Armada et al., 2013). The gain of TGF- $\beta$ function demonstrated that when an epithelial (low TGF- $\beta$ production) cell line is chronically incubated with TGF- $\beta$, significant decreases in OCR are observed at all levels: basal, ATP-linked and maximal. Cytokine-induced inflammation caused an increase in maximal OCR, as well as in the percentage of OCR dedicated to ATP synthesis. Neu5Ac-inhib decreased the respiratory capacity of the mitochondria, possibly through a negative feedback loop through an increase in ManNAc. However, this mechanism warrants further investigation.

Glycosylation is a crucial modification for final protein assembly, vesicle packing and trafficking to the cell membrane. Inhibition of this process is likely to reduce protein translation in the ER. MMPs, ADAMTSs and their regulators, TIMPs, are affected by the degree of glycosylation to modulate expression and function. For example, MMP-3 has been shown to accumulate in rheumatoid arthritis with increased expression of O-GlcNAc (Takeshita et al., 2016). Cleavage of outer arm fucose residues from the $N$-glycans of TIMP-1 or knockdown of both FUT4 and FUT7 enhance the MMP-binding and efficacy of TIMP-1 (Kim et al., 2013). MMP-13 expression was reduced by both Neu5Ac-inhib and Fucoseinhib, indicating that it was possible to diminish the inflammatory response mounted by the cell through reduced protein synthesis. Glycosylation inhibitors inhibit the trafficking of proteins through the GA due to hypoglycosylation and ER stress (Blackburn et al., 2018). However, this reduction in protein synthesis is non-specific and is likely to have undesired reductions in the synthesis of critical regulatory proteins. While studies have shown that MMP activity may be altered depending on the occupation of glycosylation sites and terminal glycosylated motifs on the enzyme (Boon et al., 2016), the activity of MMPs was not measured in the present study. The reduction in MMP secretion suggested either global inhibition of protein synthesis, non-specific to proteases or inhibition of inflammatory signalling to induce upregulation of catabolic enzymes. It is likely due to a combination of both processes.

CD44 N-linked glycosylation plays a significant role in cell attachment and migration (Rodgers et al., 2011; Sackstein et al., 2008). Inhibition of fucosylation diminishes sialyl-Lewis X/A motif and, thus, reduces E-selectin ligand expression. $\alpha-(1,3)$ fucosyltransferase upregulation can induce potent E-selectin binding (Sackstein et al., 2008). Sialylation is involved in cellular mechanisms that govern attachment and migration. It was previously shown that upregulated ST6Gal1 expression strongly inhibits monocyte-transendothelial migration through a
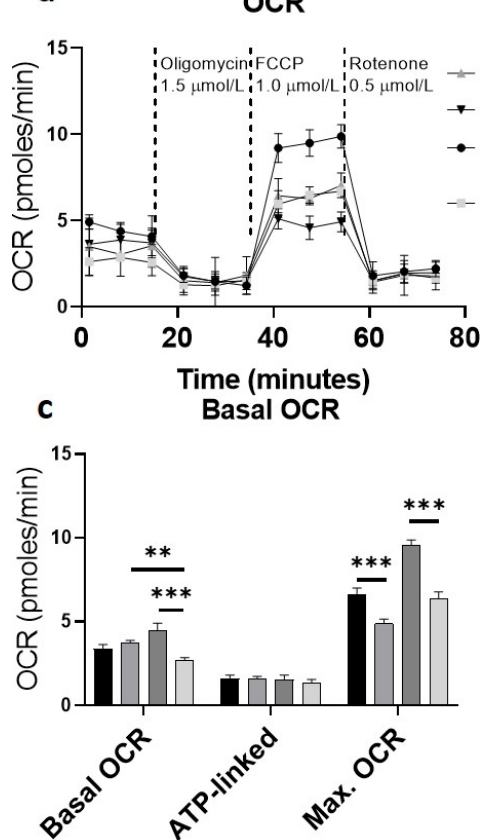

b

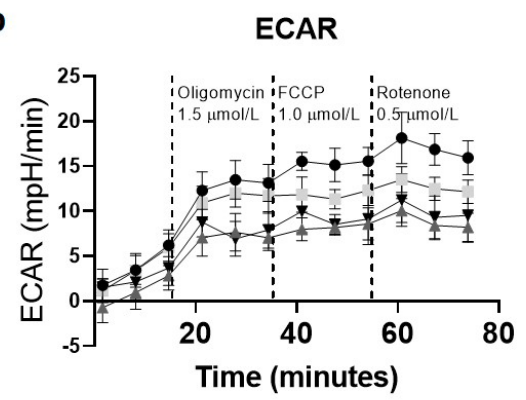

d

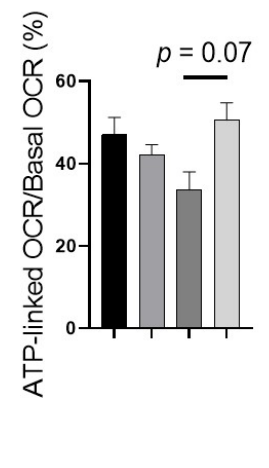

- Control

$\square$ 3Fax-Peracetyl Neu5Ac

$\square$ IL-1 $\beta /$ IL-6/TNF- $\alpha$ 3Fax-Peracetyl Neu5Ac/ IL-1 $\beta / / L-6 / T N F-\alpha$

Fig. 10. Mitochondrial dysfunction in NP cell inflammation was ameliorated by sialylation inhibition. Seahorse analysis of mitochondrial respiratory capacity in NP cells in a model of inflammation. Cells were incubated $30 \mathrm{~min}$ prior experiment in XF assay medium supplemented with $5 \mathrm{mmol} / \mathrm{L}$ glucose and $2 \mathrm{mmol} / \mathrm{L}$ glutamine and subsequently injected with oligomycin $(1 \mu \mathrm{mol} / \mathrm{L}), \mathrm{FCCP}(1.5 \mu \mathrm{mol} / \mathrm{L})$, antimycin $(1 \mu \mathrm{mol} / \mathrm{L})$ and rotenone $(1 \mu \mathrm{mol} / \mathrm{L})$. (a,c) Continuous OCR values $(\mathrm{mpH} / \mathrm{min})$ and $(\mathbf{b})$ ECAR values (pmoles/min) are shown. (d) The percentage of ATP-linked OCR was calculated as ATP-linked OCR/basal OCR. ${ }^{*} p<0.05$, ${ }^{* *} p<0.01,{ }^{* * *} p<0.001 . n=3$. One-way ANOVA. Data presented as mean \pm SEM. 
sialylation of $\beta$-catenin (Zhang et al., 2018), while ST6Gal1-mediated sialylation also promotes integrin $\beta 1$ function in adhesion and migration of colonic cancer cells (Lee et al., 2010) and CHO cells (Shi et al., 2017). An increase in cell migration is observed in desialylated endometrial stromal cells after neuraminidases activity (Maignien et al., 2019), where desialylation is measured using SNA, an $\alpha-(2,6)$ sialic acid-binding lectin. The disparity in the contradictory role of sialylation in migration, especially in cancer cell lines, can be attributed to the upregulation of $\beta$-galactoside $\alpha-(2,6)$ sialyltransferase 1 (Lu et al., 2016). The increased cell migration after sialylation inhibition observed in vitro in NP cells in the present study may be attributed to the net positive charge on the cell surface. The net positive charge created an electrostatic attraction with the negatively charged tissue culture plastic, driving cell migration. This would be a favourable cell surface modification for cell integration into a negatively charged biomaterial such as a hyaluronic acid hydrogel.

The role of fucosylation in cell migration may be explained much more simply. Defucosylation inhibits cell migration, whereas FUT8 deficiency suppresses cell migration by impacting the core fucosylation of E-cadherin and the downstream FAK/ integrin pathway (Chen et al., 2013; Isaji et al., 2006; Liu et al., 2020). Reversely, upregulated fucosylation through FUT1,2,3,6 and 8 increases cell migration and is associated with poor prognosis in non-small cell lung cancer (Park et al., 2020) and hepatoma (Wu and Chen, 2009). This inhibition is not favourable as a cell surface modification as the primary effect is core fucose inhibition and decreased cell migration. While outer arm fucosylation is aberrantly expressed in NP cells in degeneration, amelioration through global inhibition causes detrimental loss of core fucosylation.

\section{Conclusions}

The glycosignature of the NP cells in healthy and diseased tissues has been characterised and a validated inflammatory model of IVD degeneration has been developed. Small-molecule fluorinated sugar analogues (3Fax-Peracetyl Neu5Ac; 2F-Peracetyl-Fucose) were used to inhibit sialylation and fucosylation in an in vitro model of inflammation, to investigate their effects on glycosignature, cell metabolism, ECM synthesis and cell migration. In the in vitro model of IVD degeneration, cytokineinduced inflammation induced hypersialylation and hyperfucosylation in human NP cells. However, this modification was inhibited by Neu5Ac-inhib and Fucose-inhib, respectively. Inhibition of sialylation and fucosylation modulated cell migration and protein translation of catabolic enzymes in response to inflammation. Small-molecule inhibitors of glycosylation appeared to have a profound effect on cell secretome, influencing protein synthesis, matrix deposition and cell surface glycosylation. Neu5Ac-inhib retained the NP cell glyco-phenotype in inflammation, diminished catabolic enzyme release and increased cell motility. However, Fucose-inhib had deleterious effects on cell migration and ECM synthesis. When introducing a biomaterial into the IVD, tissue integration and material resorption are essential parameters that can be influenced by modulation of sialylated motifs. Neu5Ac-inhib may have a potentially beneficial therapeutic effect delivered by a carrier system in treating IVD degeneration. The role of sialylation and fucosylation have been investigated in the NP cell in an in vitro model of IVD degeneration and potential glycomicbased mechanisms of degeneration and disease targets have been identified.

\section{Acknowledgements}

The authors sincerely thank Mr Patrick Kiely and staff, Our Lady's Children's Hospital, Crumlin for providing IVD tissue, Emer Bonham at UCD Conway for access to tissue processing facilities and Joao Marques Garcia at Utrecht University for the collection and preparation of the IVD material. This publication is the result of research conducted with the financial support of the College of Medicine, Nursing and Health Sciences, NUI Galway/Science Foundation Ireland (SFI) and the European Regional Development Fund (Grant Number 13/RC/2073). The authors acknowledge the facilities and scientific and technical assistance of the Centre for Microscopy and Imaging, Genomics and Screening Core, a facility that is funded by NUI Galway and the Irish Government's Programme for Research in Third Level Institutions, Cycles 4 and 5, National Development Plan 20072013. The authors declare no conflict of interest.

\section{References}

Adams MA, Dolan P, McNally DS (2009) The internal mechanical functioning of intervertebral discs and articular cartilage, and its relevance to matrix biology. Matrix Biol 28: 384-389.

Adams MA, Lama P, Zehra U, Dolan P (2015) Why do some intervertebral discs degenerate, when others (in the same spine) do not? Clin Anat 28: 195-204.

Becker DJ, Lowe JB (2003) Fucose: biosynthesis and biological function in mammals. Glycobiology 13: 41-53.

Benya PD, Padilla SR, Nimni ME (1978) Independent regulation of collagen types by chondrocytes during the loss of differentiated function in culture. Cell 15: 1313-1321.

Bhide GP, Colley KJ (2017) Sialylation of N-glycans: mechanism, cellular compartmentalization and function. Histochem. Cell Biol 147: 149-174.

Blackburn JB, Kudlyk T, Pokrovskaya I, Lupashin VV (2018) More than just sugars: conserved oligomeric 
Golgi complex deficiency causes glycosylationindependent cellular defects. Traffic 19: 463-480.

Boon L, Ugarte-Berzal E, Vandooren J, Opdenakker G (2016) Glycosylation of matrix metalloproteases and tissue inhibitors: present state, challenges and opportunities. Biochem J 473: 1471-1482.

Buckwalter J (1995) Aging and degeneration of the human intervertebral disc. Spine (Phila Pa 1976) 20: 1307-1314.

Chen C-Y, Jan Y-H, Juan Y-H, Yang C-J, Huang M-S, Yu C-J, Yang P-C, Hsiao M, Hsu T-L, Wong C-H (2013) Fucosyltransferase 8 as a functional regulator of non-small cell lung cancer. Proc Natl Acad Sci U S A 110: 630-635.

Chen X, Varki A (2010) Advances in the biology and chemistry of sialic acids. ACS Chem Biol 5: 163176.

Collin EC, Kilcoyne M, White SJ, Grad S, Alini M, Joshi L, Pandit AS (2016) Unique glycosignature for intervertebral disc and articular cartilage cells and tissues in immaturity and maturity. Sci Rep 6: 23062. DOI: 10.1038/srep23062.

Da Silva Correia J, Ulevitch RJ (2002) MD-2 and TLR4 N-linked glycosylations are important for a functional lipopolysaccharide receptor. J Biol Chem 277: 1845-1854.

Delmotte P, Degroote S, Lafitte JJ, Lamblin G, Perini JM, Roussel P (2002) Tumor necrosis factor $\alpha$ increases the expression of glycosyltransferases and sulfotransferases responsible for the biosynthesis of sialylated and/or sulfated Lewis X epitopes in the human bronchial mucosa. J Biol Chem 277: 424-431.

Fearing BV, Hernandez PA, Setton LA, Chahine NO (2018) Mechanotransduction and cell biomechanics of the intervertebral disc. JOR Spine 1: e1026. DOI: 10.1002/jsp2.1026.

Gao G, Chang F, Zhang T, Huang X, Yu C, Hu Z, Ji M, Duan Y (2019) Naringin protects against interleukin $1 \beta$ (IL-1 $\beta$ )-induced human nucleus pulposus cells degeneration via downregulation nuclear factor kappa B (NF-kB) pathway and p53 expression. Med Sci Monit 25: 9963-9972.

Groux-Degroote S, Krzewinski-Recchi MA, Cazet A, Vincent A, Lehoux S, Lafitte JJ, Van Seuningen I, Delannoy P (2008) IL-6 and IL-8 increase the expression of glycosyltransferases and sulfotransferases involved in the biosynthesis of sialylated and/or sulfated Lewis ${ }^{\mathrm{x}}$ epitopes in the human bronchial mucosa. Biochem J 410: 213-223.

Haab BB (2012) Using lectins in biomarker research: Addressing the limitations of sensitivity and availability. Proteomics Clin Appl 6: 346-350.

Haab BB, Klamer Z (2020) Advances in tools to determine the glycan-binding specificities of lectins and antibodies. Mol Cell Proteomics 19: 224-232.

Hamouda H, Ullah M, Berger M, Sittinger M, Tauber R, Ringe J, Blanchard V (2013) N-glycosylation profile of undifferentiated and adipogenically differentiated human bone marrow mesenchymal stem cells: towards a next generation of stem cell markers. Stem Cells Dev 22: 3100-3113.
Henry S, Oriol R, Samuelsson B (1995) Lewis histo-blood group system and associated secretory phenotypes. Vox Sang 69: 166-182.

Higai K, Ishihara S, Matsumoto K (2006) NFkB-p65 dependent transcriptional regulation of glycosyltransferases in human colon adenocarcinoma HT-29 by stimulation with tumor necrosis factor $\alpha$. Biol Pharm Bull 29: 2372-2377.

HinderlichS, Weidemann W, Yardeni T, Horstkorte R, Huizing M (2015) UDP-GlcNAc 2-epimerase/ ManNAc kinase (GNE): a master regulator of sialic acid synthesis. Top Curr Chem 366: 97-138.

Isaji T, Sato Y, Zhao Y, Miyoshi E, Wada Y, Taniguchi N, Gu J (2006) N -glycosylation of the $\beta$-propeller domain of the integrin $\alpha 5$ subunit ss essential for $\alpha 5 \beta 1$ heterodimerization, expression on the cell surface, and its biological function. J Biol Chem 281: 33258-33267.

Jürgensen HJ, Madsen DH, Ingvarsen S, Melander MC, Gårdsvoll H, Patthy L, Engelholm LH, Behrendt N (2011) A novel functional role of collagen glycosylation: Interaction with the endocytic collagen receptor uPARAP/ENDO180. J Biol Chem 286: 3273632748.

Kazezian Z, Li Z, Alini M, Grad S, Pandit A (2017) Injectable hyaluronic acid down-regulates interferon signaling molecules, IGFBP3 and IFIT3 in the bovine intervertebral disc. Acta Biomater 52: 118-129.

Kim HI, Saldova R, Park JH, Lee YH, Harvey DJ, Wormald MR, Wynne K, Elia G, Kim HJ, Rudd PM, Lee ST (2013) The presence of outer arm fucose residues on the $\mathrm{N}$-glycans of tissue inhibitor of metalloproteinases- 1 reduces its activity. J Proteome Res 12: 3547-3560.

Kim YJ, Varki A (1997) Perspectives on the significance of altered glycosylation of glycoproteins in cancer. Glycoconj J 14: 569-576.

Komekado H, Yamamoto H, Chiba T, Kikuchi A (2007) Glycosylation and palmitoylation of Wnt-3a are coupled to produce an active form of Wnt-3a. Genes Cells 12: 521-534.

Kyprianou P, Betteridge A, Donald ASR, Watkins WM (1990) Purification of the blood group H gene associated $\alpha$-2-1-fucosyltransferase from human plasma. Glycoconj J 7: 573-588.

Lee M, Lee HJ, Seo WD, Park KH, Lee YS (2010) Sialylation of integrin $\beta 1$ is involved in radiationinduced adhesion and migration in human colon cancer cells. Int J Radiat Oncol Biol Phys 76: 15281536.

Legault DJ, Kelly RJ, Natsuka Y, Lowe JB (1995) Human $\alpha(1,3 / 1,4)$-fucosyltransferases discriminate between different oligosaccharide acceptor substrates through a discrete peptide fragment. J Biol Chem 270: 20987-20996.

Li Y, Chen X (2012) Sialic acid metabolism and sialyltransferases: natural functions and applications. Appl Microbiol Biotechnol 94: 887-905.

Liu G-J, Jia L-Y, Xing G-W (2020) Probing sialidases or siglecs with sialic acid analogues, clusters and precursors. Asian J Org Chem 9: 42-52. 
Liu Y-C, Yen H-Y, Chen C-Y, Chen C-H, Cheng P-F, Juan Y-H, Chen C-H, Khoo K-H, Yu C-J, Yang P-C, Hsu T-L, Wong C-H (2011) Sialylation and fucosylation of epidermal growth factor receptor suppress its dimerization and activation in lung cancer cells. Proc Natl Acad Sci U S A 108: 1133211337.

López-Armada MJ, Riveiro-Naveira RR, Vaamonde-García C, Valcárcel-Ares MN (2013) Mitochondrial dysfunction and the inflammatory response. Mitochondrion 13: 106-118.

Lu J, Isaji T, Im S, Fukuda T, Kameyama A, Gu J (2016) Expression of N-acetylglucosaminyltransferase III suppresses $\alpha 2,3$-sialylation, and its distinctive functions in cell migration are attributed to $\alpha 2,6-$ sialylation levels. J Biol Chem 291: 5708-5720.

Maignien C, Santulli P, Chouzenoux S, GonzalezForuria I, Marcellin L, Doridot L, Jeljeli M, Grange P, Reis FM, Chapron C, Batteux F (2019) Reduced $\alpha-2,6$ sialylation regulates cell migration in endometriosis. Hum Reprod 34: 479-490.

Miyoshi E, Noda K, Yamaguchi Y, Inoue S, Ikeda Y, Wang W, Ko JH, Uozumi N, Li W, Taniguchi N (1999) The alpha1-6-fucosyltransferase gene and its biological significance. Biochim Biophys Acta 1473: 9-20.

Mohd Isa IL, Abbah SA, Kilcoyne M, Sakai D, Dockery P, Finn DP, Pandit A (2018) Implantation of hyaluronic acid hydrogel prevents the pain phenotype in a rat model of intervertebral disc injury. Sci Adv 4: eaaq0597. DOI: 10.1126/sciadv. aaq0597.

Montgomery A, Szabo R, Skropeta D, Yu H (2016) Computational characterisation of the interactions between human ST6Gal I and transition-state analogue inhibitors: insights for inhibitor design. J Mol Recognit 29: 210-222.

Natoni A, Bohara R, Pandit A, O’Dwyer M (2019) Targeted approaches to inhibit sialylation of multiple myeloma in the bone marrow microenvironment. Front Bioeng Biotechnol 7: 252. DOI: 10.3389/ fbioe.2019.00252.

Natoni A, Farrell ML, Harris S, Falank C, KirkhamMcCarthy L, Macauley MS, Reagan MR, O'Dwyer M (2020) Sialyltransferase inhibition leads to inhibition of tumor cell interactions with E-selectin, VCAM1, and MADCAM1, and improves sur vival in a human multiple myeloma mouse model. Haematologica 105: 457-467.

Pabst M, Wu SQ, Grass J, Kolb A, Chiari C, Viernstein H, Unger FM, Altmann F, Toegel S (2010) IL-1 $\beta$ and TNF- $\alpha$ alter the glycophenotype of primary human chondrocytes in vitro. Carbohydr Res 345: 1389-1393.

Park S, Lim JM, Chun JN, Lee S, Kim TM, Kim DW, Kim SY, Bae DJ, Bae SM, So I, Kim HG, Choi JY, Jeon $\mathrm{JH}$ (2020) Altered expression of fucosylation pathway genes is associated with poor prognosis and tumor metastasis in non-small cell lung cancer. Int J Oncol 56: 559-567.
Paulson J, Colley J (1989) Glycosyltransferases: structure, localization and control of cell type-specific glycosylation. J Biol Chem 264: 17615-17618.

Pfirrmann CWA, Metzdorf A, Zanetti M, Hodler J, Boos N (2001) Magnetic resonance classification of lumbar intervertebral disc degeneration. Spine (Phila Pa 1976). 26: 1873-1878.

Raman R, Raguram S, Venkataraman G, Paulson JC, Sasisekharan R (2005) Glycomics: An integrated systems approach to structure-function relationships of glycans. Nat Methods 2: 817-824.

Richardson SM, Ludwinski FE, Gnanalingham KK, Atkinson RA, Freemont AJ, Hoyland JA (2017) Notochordal and nucleus pulposus marker expression is maintained by sub-populations of adult human nucleus pulposus cells through aging and degeneration. Sci Rep 7: 1-11.

Rillahan CD, Antonopoulos A, Lefort CT, Sonon R, Azadi P, Ley K, Dell A, Haslam SM, Paulson JC (2012) Global metabolic inhibitors of sialyl- and fucosyltransferases remodel the glycome. Nat Chem Biol 8: 661-668.

Rodgers AK, Nair A, Binkley PA, Tekmal R, Schenken RS (2011) Inhibition of CD44 N- and O-linked glycosylation decreases endometrial cell lines attachment to peritoneal mesothelial cells. Fertil Steril 95: 823-825.

Ryczko MC, Pawling J, Chen R, Abdel Rahman AM, Yau K, Copeland JK, Zhang C, Surendra A, Guttman DS, Figeys D, Dennis JW (2016) Metabolic reprogramming by hexosamine biosynthetic and golgi N-glycan branching pathways. Sci Rep 6: 1-15.

Sackstein R, Merzaban JS, Cain DW, Dagia NM, Spencer JA, Lin CP, Wohlgemuth R (2008) Ex vivo glycan engineering of CD44 programs human multipotent mesenchymal stromal cell trafficking to bone. Nat Med 14: 181-187.

Shi G, Du Y, Li Y, An Y, He Z, Lin Y, Zhang $R$, Yan $X$, Zhao J, Yang S, Brendan PNK, Liu F (2017) Cell recognition molecule L1 regulates cell surface glycosylation to modulate cell survival and migration. Int J Med Sci 14: 1276-1283.

Srivastava A, Isa ILM, Rooney P, Pandit A (2017) Bioengineered three-dimensional diseased intervertebral disc model revealed inflammatory crosstalk. Biomaterials 123: 127-141.

Takahata M, Iwasaki N, Nakagawa H, Abe Y, Watanabe T, Ito M, Majima T, Minami A (2007) Sialylation of cell surface glycoconjugates is essential for osteoclastogenesis. Bone 41: 77-86.

Takeshita M, Kuno A, Suzuki K, Matsuda A, Shimazaki H, Nakagawa T, Otomo Y, Kabe Y, Suematsu M, Narimatsu H, Takeuchi T (2016) Alteration of matrix metalloproteinase-3 O-glycan structure as a biomarker for disease activity of rheumatoid arthritis. Arthritis Res Ther 18: 112. DOI: 10.1186/s13075-016-1013-2.

Thompson JP, Pearce RH, Schechter MT, Adams ME, Tsang IK, Bishop PB (1990) Preliminary evaluation of a scheme for grading the gross 
morphology of the human intervertebral disc. Spine (Phila Pa 1976) 15: 411-415

Toegel S, Bieder D, André S, Altmann F, Walzer SM, Kaltner H, Hofstaetter JG, Windhager R, Gabius H-J (2013) Glycophenotyping of osteoarthritic cartilage and chondrocytes by RT-qPCR, mass spectrometry, histochemistry with plant/human lectins and lectin localization with a glycoprotein. Arthritis Res Ther 15: R147. DOI: 10.1186/ar4330.

van den Akker GGH, Surtel DAM, Cremers A, Rodrigues-Pinto R, Richardson SM, Hoyland JA, van Rhijn LW, Welting TJM, Voncken JW (2014) Novel immortal human cell lines reveal subpopulations in the nucleus pulposus. Arthritis Res Ther 16: R135. DOI: 10.1186/ar4597.

Watanabe T, Higuchi K, Hamaguchi M, Shiba M, Tominaga K, Fujiwara Y, Matsumoto T, Arakawa $\mathrm{T}$ (2004) Monocyte chemotactic protein-1 regulates leukocyte recruitment during gastric ulcer recurrence induced by tumor necrosis factor- $\alpha$. Am J Physiol Gastrointest. Liver Physiol 287: 50-54.

Wu LH, Shi BZ, ZhaoQL, Wu XZ(2009)Fucosylated glycan inhibition of human hepatocellular carcinoma cell migration through binding to chemokine receptors. Glycobiology 20: 215-223.

Zhang J, Liu Y, Deng X, Chen L, Yang X, Yu C (2018) ST6GAL1 negatively regulates monocyte transendothelial migration and atherosclerosis development. Biochem Biophys Res Commun 500: 249-255.

Zheng CJ, Chen J (2015) Disc degeneration implies low back pain. Theor Biol Med Model 12: 24. DOI: 10.1186/s12976-015-0020-3.

\section{Discussion with Reviewers}

Catarina Leite Pereira: This study used cells from different donors. Diseased donors have a larger age range. Did the authors find out any correlation with age in the observed results? If data were aggregated by age groups, would this have an influence on the glyco-pattern? What about the degenerative levels? Can the glycome correlate with Pfirrmann grades and be used as an indicator of disease progression? Authors: This is a very interesting question and something we have considered during the study. An initial screening was performed across nine donors of degenerated IVD tissue and a regressional analysis was performed based on age and grade of disease; however, no differences were observed across donors. This may be due to small sample size but also to the necessity of passaging cells before analysis, which may occlude sensitive motif changes in the glycosignature. We would anticipate that a high-powered study using techniques such as lectin microarray and principal component analysis may discern age- and grade-dependent motifs.

Catarina Leite Pereira: How do the authors envisage the application of the glycome as a target for IVD disease progression? Which novel therapies can arise from the full characterisation of IVD "glyco-pattern"? Authors: Glyco-functionalisation of implantable biomaterials would be the next intuitive step in this line of investigation. There are multiple approaches available to promote and inhibit specific glycosylation changes to modulate the glycome towards a healthy and regenerative glycophenotype. It is unlikely that glycome-based targets are sufficient to halt degeneration and restore normal disc function alone; however, glyco-functionalised materials may improve cell migration, cell-material interaction, downstream signalling, protein synthesis and trafficking towards efficacious material responses.

Reviewer 2: The in vitro model developed in the present work was in 2D. While the authors did evaluate maintenance of NP phenotype in 2D conditions, do they envisage differing outcomes, such as the effects of the inhibitors, if the NP cells were in $3 \mathrm{D}$ ?

Authors: The effect of sialylation inhibition on cell survival and proliferation was briefly investigated in a 3D cell culture medium but no differences versus controls were observed. However, it would be interesting to investigate the cell-material interactions in $3 \mathrm{D}$ cultures using biomaterial-based structures, such as collagen scaffolds, since integrin- and selectinmediated cell-matrix interactions are tightly regulated by protein glycosylation, specifically sialylation and fucosylation through sialyl-Lewis- $X$ motifs.

Reviewer 2: How do the authors envision these inhibitors being applied clinically: at which stage of degeneration would they most likely be applied, how would they be applied? Have the authors anticipated unwanted side effects from the molecules besides the intended target?

Authors: In IVD degeneration, these small-molecule inhibitors can be loaded into injectable hydrogel formulations for local delivery into the disc, with the potential to promote cell migration into the material, modulate cell metabolism and inhibit proinflammatory pathways. We anticipate this approach to be most efficacious in early degeneration while native cell populations remain high. Sialylation inhibition is already gaining popularity in other fields, such as oncology, as sialylation plays a crucial role in cell migration and metastatic disease. Such applications require systemic delivery of the drug known to be highly nephrotoxic, necessitating targeted delivery. However, in the case of IVD degeneration, local drug delivery on a carrier into an avascular space is highly unlikely to be released into systemic circulation at a high enough concentration to cause kidney injury.

Editor's note: The Guest Editor responsible for this paper was Andrea Vernengo. 